\title{
Du polymorphisme au complexe d'espèces : combien d'agents pathogènes sont impliqués dans la nécrose du collet du colza?
}

\author{
T Rouxel *, C Gall, MH Balesdent \\ INRA, station de pathologie végétale, route de Saint-Cyr, F-78026 Versailles cedex, France
}

(Reçu le 29 juillet 1994; accepté le 8 août 1994)

\begin{abstract}
Résumé - La nécrose du collet des crucifères, ou "phoma du colza", est une maladie qui a subi une extension considérable à la suite de l'intensification de la culture du colza en Europe, au Canada ou en Australie. Phoma lingam (Tode ex Fr) Desm est reconnu depuis de nombreuses années comme étant l'agent responsable de la maladie. La forme sexuée du parasite, phase quasi systématique du cycle, a été identifiée dans les années 1960 à Leptosphaeria maculans (Desm) Ces et de Not. Dès 1927, 2 groupes de souches isolées de Brassica cultivées sont distingués, selon des critères pathologiques et culturaux d'une fiabilité limitée. Sur la base de ces critères, on a considéré que l'on était en présence de 2 pathotypes : «pathogène" et «faiblement pathogène». Le développement, au début des années 1990, de méthodes fines de caractérisation (isozymes, analyses moléculaires, etc) a démontré une distance génétique importante entre les 2 groupes de souches, suggérant qu'il pouvait s'agir de 2 espèces distinctes. Des travaux récents montrent par ailleurs que les souches ufaiblement pathogènes" représentent, en elles-mêmes, une entité complexe regroupant au moins 3 groupes de souches génétiquement distantes. Des observations préliminaires suggèrent en outre que le type prépondérant serait différent en Australie, en Europe ou au Canada. Enfin, la présence de souches proches mais encore très peu étudiées, parasitant les crucifères adventices accroît la complexité du pathosystème. La discrimination originelle en 2 "pathotypes" a été fortement préjudiciable au développement d'analyses plus poussées des populations en présence et de leur interaction avec les crucifères. Par conséquent, une cartographie de l'occurrence des différents types de souches, une réévaluation de leur symptomatologie respective et une analyse de l'incidence des souches issues de crucifères adventices sur les cultures de colza sont nécessaires pour une meilleure appréciation de l'importance de chaque groupe de souches dans la maladie, et un meilleur contrôle de celle-ci.
\end{abstract}

Leptosphaeria maculans / Phoma lingam / colza / nécrose du collet / complexe d'espèces

Summary - How many pathogens do cause blackleg disease in crucifers? Blackleg in crucifers has become a disease of international importance following the tremendous increase in oilseed rape acreage in Europe, Canada and Australia. The causative agent of the disease has been described as Leptosphaeria maculans (Desm) Ces et de Not, an ascomycete whose anamorph is Phoma lingam (Tode ex Fr) Desm. The pathogen is known to be highly polymorphic in cultural characteristics and pathogenicity. Isolates obtained from Brassica sp in the early 1920s were distinguished as belonging to either a 'pathogenic' pathotype or a 'weakly pathogenic' pathotype. However, the reliability of the morphological, and even the pathogenic, criteria for a discrimination of isolates has been questioned. 'Modern methods' for the study of the polymorphism of fungi, ie isozymic and molecular techniques, usually allow an unequivo$\mathrm{cal}$ discrimination of the 2 groups. Moreover, these techniques recently demonstrated an important genetic distance between the 2 groups of isolates, suggesting that they may actually belong to 2 distinct species. The 'weakly pathoge-

* Correspondance et tirés à part 
nic' group can be further separated into 3 genetically distinct subgroups. Moreover, it has been suggested that the prevalent subgroup could be different in Europe, Australia or America. Finally, 4 other $\mathrm{L}$ maculans, pathogenic to different species of cruciferous weeds have been described in Canada. Since only pathogenic and morphological criteria were studied, the relationship of these additional $\mathrm{L}$ maculans to the 'pathogenic' group or 'weakly pathogenic' groups obtained from Brassica is still unknown. The original discrimination into 2 pathotypes has been highly prejudicial to the understanding and study of this pathosystem. As a consequence, the pathogenicity of each group, or subgroup of isolate to crucifers and its involvement in the blackleg disease has to be reconsidered.

\section{Leptosphaeria maculans / Phoma lingam / oilseed rape / blackleg disease / species complex}

\section{INTRODUCTION}

«Une maladie, une plante, un agent pathogène». Cette idée simple est à la base de la plupart des stratégies de lutte contre les maladies des plantes. Mais il ne s'agit que d'une simplicité apparente car les espèces pathogènes sont bien souvent caractérisées par leur polymorphisme et l'aptitude qu'elles ont à varier pour s'adapter à de nouvelles contraintes (résistances de la plante, fongicides, etc). Les parasites fongiques, en particulier, semblent avoir développé, outre une reproduction sexuée très efficace chez certaines espèces, des modes de variation génétique propres ayant pour conséquence d'amplifier leur adaptabilité (Kistler et Miao, 1992).

Si on s'est, dans les années passées, beaucoup intéressé à une telle variabilité pour estimer les risques liés à l'introduction de nouveaux gènes de résistance ou pour estimer l'efficacité et la durabilité de nouveaux fongicides, un degré supérieur de complexité a rarement été envisagé. Ainsi, le concept de "complexe parasitaire", où plusieurs espèces seraient associées pour causer une maladie, a été peu appréhendé. En fait, en l'absence de techniques performantes de caractérisation des populations parasitaires, les méthodes basées sur la morphologie des souches en culture ou au champ ont eu cours quasiment exclusivement jusqu'à la fin des années 1980. Dans le cas de la «nécrose du collet des crucifères", l'extrême variabilité morphologique de l'agent causal a été reconnue dès son identification. Très rapidement, des méthodes de lutte efficaces ont été développées : techniques culturales et surtout utilisation de cultivars de colza tolérants, développant tardivement la nécrose du collet préjudiciable au rendement. Cette situation n'a pas particulièrement incité à analyser les populations du parasite dont le cycle et les conditions favorables à sa dissémination avaient été caractérisés par ailleurs. Dès 1975, des stratégies d'amélioration du colza basées sur le transfert de gènes de résistance présents chez des espèces proches ont toutefois été dévelop- pées pour pallier la perte progressive d'efficacité des tolérances utilisées jusqu'alors (Roy et Reeves, 1975 ; Roy, 1978). La recrudescence récente de la maladie sur tous les continents s'est accompagnée d'interrogations plus pointues concernant la structure des populations du parasite. Ainsi, à la fin des années 1980, des analyses performantes, mais encore très partielles, des populations en présence ont révélé une complexité inattendue. La présence de 2 espèces fongiques, encore désignées sous le même nom "Leptosphaeria maculans" est maintenant reconnue sur tous les continents sans que la participation de l'une, de l'autre ou des 2 associées dans le développement de tous les symptômes de la maladie soit établie. Dans ces conditions, les stratégies de lutte restent empiriques tant que l'on ne sait pas si elles doivent être dirigées contre une espèce fongique donnée ou contre un complexe d'espèces.

Le présent article a pour objet de donner un aperçu des connaissances actuelles concernant le(s) champignon(s) responsable(s) du «phoma du colza». Il a surtout pour ambition de donner un aperçu de la complexité que peut revêtir un pathosystème et de mettre en garde contre une transposition de conclusions tirées de travaux effectués dans des conditions de milieu ou de culture bien différentes de celles qui peuvent prévaloir en Europe.

\section{LA MALADIE}

L'importance économique de la nécrose du collet des crucifères est reconnue dès le début du $x^{e}$ siècle (pour une revue : Henderson, 1918). En 1897, des pertes de rendement de l'ordre de 25 à $90 \%$ sont observées sur chou et chou-fleur en Australie du Sud. L'importance de la maladie sur chou fourrager est rapportée en 1909 dans l'est de la France. Dans de nombreux états des ÉtatsUnis, des pertes pouvant atteindre $75 \%$ sur chou et chou-fleur sont signalées en 1912. 
Mais c'est surtout dans la seconde moitié du siècle, avec l'intensification de la culture du colza (la production de graines de colza de la CEE est passée de 300000 t en 1961 à plus de 6 millions de tonnes en 1992-1993; Austin et al, 1986 ; Bonnet, 1994), que la nécrose du collet des crucifères est devenue une maladie d'importance économique primordiale, allant jusqu'à retarder ou empêcher le développement de cette culture dans certaines parties du globe.

Une des premières épidémies a été décrite en France, dans la région parisienne (Darpoux et al, 1957). Selon les champs considérés, une attaque de $50 \%$ à $80 \%$ des plantes était observée. L'incidence de la maladie en France a été énorme à partir de 1964, une baisse du rendement moyen de $40 \%$ étant observée entre 1964 et 1967 (Lacoste et al, 1969). Des effets similaires ont été observés en Allemagne, où $70 \%$ des plantes étaient affectées certaines années et où, comme en France, la maladie est désormais répandue dans toutes les régions productrices de colza (Krüger, 1983). L'intensification de la culture du colza en Angleterre, à la fin des années 1970, a, là aussi, conduit à un développement spectaculaire de la maladie, et des pertes de rendement de l'ordre de $50 \%$ dans certaines parcelles ont été observées en 1977 (Gladders et Musa, 1980).

En Australie, le colza a été introduit en 1968. En 1972, 249000 ha étaient cultivés dans le sud et l'ouest de l'Australie (McGee et Emmett, 1977). Cette même année, une épidémie entraîna de sévères pertes de rendement et, en conséquence, la surface cultivée en colza diminua de 96\% entre 1972 et 1974 (Roy et Reeves, 1975 ; McGee et Emmett, 1977). L'amélioration de la tolérance des cultivars de colza, en particulier à l'aide de géniteurs de résistance français, a permis, à partir de 1978, d'obtenir des niveaux de pertes à la récolte tolérables, autorisant ainsi le développement de la culture en Australie (Roy et Reeves, 1975 ; Roy, 1978).

Au Canada, la maladie a longtemps été considérée comme d'importance économique limitée. Dans l'ouest canadien, jusqu'au milieu des années 1970, elle se traduisait par des pertes à la récolte estimées à 1 ou 2\% (Gugel et Petrie, 1992). Des pertes de rendement importantes, attribuées par les auteurs à des souches "virulentes» du champignon, ont été décrites très ponctuellement au Saskatchewan, en 1975 (McGee et Petrie, 1978 ; Petrie, 1978). À partir de ces points initiaux d'infection, la maladie s'est ensuite répandue très rapidement et, en 1982, une perte moyenne de rendement de $6 \%$ était estimée pour l'ensemble du Saskatchewan, pou- vant ponctuellement atteindre 56\% (Gugel et Petrie, 1992). En 1986, la maladie était présente dans $65 \%$ des parcelles analysées au Saskatchewan et a continué à se répandre dans la province et d'autres parties du Canada (Manitoba, Ontario, Alberta, etc) (Gugel et Petrie, 1992). Cette dissémination explosive a été fortement favorisée par la culture sur une grande échelle du cultivar de colza de printemps Westar, à fort rendement mais très sensible à la maladie (Gugel et Petrie, 1992).

En Europe, puis en Australie, I'utilisation de cultivars tolérants exprimant tardivement la nécrose du collet, tels que Jet Neuf ou Darmor, a permis, pendant une dizaine d'années, un bon contrôle de la maladie au détriment sans doute de la recherche de résistances ayant pour effet une limitation des populations fongiques (Humpherson-Jones, 1983). En effet, les tolérances s'attaquent aux conséquences de l'infection, puisqu'elles ont pour objet de limiter l'expression des symptômes, et non à l'agent pathogène lui-même, ce qui a sans doute favorisé sa dissémination et son développement endémique. On assiste, ces dernières années, en Europe en particulier, à une recrudescence de la maladie sans que l'on sache vraiment si cela est dû à une augmentation de l'agressivité des populations du parasite, à une diminution de la tolérance des nouveaux cultivars, à une succession d'années climatiquement favorables à la maladie, ou à un ensemble de plusieurs de ces facteurs. Dans ces conditions, et en l'absence de traitement fongicide efficace contre ce parasite, les stratégies de lutte visant à introduire dans le colza des gènes de résistance provenant d'espèces proches, ou la recherche et la caractérisation de gènes de résistance spécifique chez le colza sont les alternatives les plus prometteuses pour peu que l'efficacité et la durabilité de telles résistances puissent être évaluées.

\section{L'AGENT PATHOGÈNE}

\section{Leptosphaeria maculans, agent causal de la nécrose du collet des crucifères}

Tode, en 1791, a décrit un champignon isolé de tiges desséchées de chou rouge (Brassica oleracea rubra) qu'il nomme Sphaeria lingam (Henderson, 1918). Desmazière, en 1849, est le premier a reconnaître le caractère pathogène du champignon sur chou et à le rattacher au genre Phoma. Après ces premières descriptions, de 
nombreux auteurs ont redécouvert ce parasite et l'ont généralement affublé de noms correspondant à cette redécouverte. Ainsi, Desmazière luimême décrit sur siliques de Brassica sp en France un Phoma siliquastrum (Desmazière, 1849) ; Saccardo, en Italie, décrit sur chou un Phoma oleracea Sacc (Saccardo, 1880, cité dans Henderson, 1918) ; von Thumen (1880, cité dans Henderson, 1918) décrit sur chou un Aposphaeria brassicae ; Rostrup (1894) décrit sur rutabaga au Danemark un Phoma napobrassicae ; et Prillieux et Delacroix décrivent en 1890 un Phoma brassicae. Ces différentes appellations, motivées par des variations morphologiques, ont toutefois été très rapidement mises sur le compte du polymorphisme de l'agent pathogène ou sur un manque de communication entre les auteurs. En effet, dès 1918 , une analyse de souches de $P$ oleracea, de $P$ brassicae et de $P$ lingam de diverses provenances a suggéré l'identité de ces 3 "espèces" (Henderson, 1918). Le nom communément admis pour la forme imparfaite de l'agent pathogène est donc Phoma lingam (Tode) Desm.

Dès 1863, Tulasne et Tulasne suggèrent une relation entre $P$ lingam et Leptosphaeria maculans. Ce n'est que bien plus tard que plusieurs auteurs ont démontré expérimentalement, dans différentes parties du globe, que $L$ maculans (Desm) Ces et de Not était bien la forme parfaite de $P$ lingam. Cette démonstration a été effectuée indépendamment en Europe continentale à partir d'ascospores isolées d'Isatis tinctoria (Müller, 1953 ; Müller et Tomasevic, 1957), en NouvelleZélande et en Australie à partir de périthèces isolés de diverses Brassica cultivées (Smith, 1956), en Angleterre à partir de souches isolées de chou de Bruxelles (Smith et Sutton, 1964), et en Amérique du Nord à partir de périthèces isolés de Thlaspi arvense, puis de nombreuses autres crucifères (Petrie, 1969).

\section{Les Leptosphaeria des crucifères}

Plusieurs autres espèces de Leptosphaeria ont été décrites sur crucifères, principalement sur la base de données morphologiques (taille des asques et des ascospores, nombre de septa chez les ascospores, etc). Ainsi Holm (1957) a décrit $L$ cesatiana (Mont ex Ces et de Not) Holm isolé de Brassica sp, $L$ conferta Niessl ex Sacc isolé de Descurainia sp et autres crucifères adventices, $L$ cylindrospora Auersw et Niessl ex Sacc isolé de Epilobium sp, $L$ johansonii Muller isolé d'Arabis $\mathrm{sp}$, et $L$ submaculans Holm isolé de Sisymbrium loeselii et autres crucifères adventices. Par ailleurs, Saccardo (1883, cité dans Petrie, 1969) décrit $L$ olericola ( $B$ et $C$ ) Sacc isolé de Brassica $\mathrm{sp}, L$ drabae (Nyl) Karst isolé de Draba sp et $L$ virginica (C et $\mathrm{E}$ ) Sacc isolé de Lepidium sp.

Les données concernant l'appartenance à une espèce donnée restent toutefois extrêmement confuses et diverses polémiques ont eu cours concernant le regroupement de diverses espèces sous un seul nom. Ainsi $L$ conferta, qui a une forme imparfaite de type Phoma, a été considéré pendant un temps comme un synonyme de $L$ maculans (Petrie, 1969). Plusieurs espèces sont morphologiquement très proches, voire indistinguables de $L$ maculans et sont ou non, selon les auteurs, considérées comme divers synonymes de $L$ maculans. C'est en particulier le cas pour $L$ submaculans (Lucas et Webster, 1967) ou $L$ cylindrospora (Petrie, 1969). À l'opposé, L napi, isolé de Brassica en Nouvelle-Zélande, et morphologiquement distinct de $L$ maculans, en particulier en ce qui concerne la taille des ascospores et le nombre de septa a ensuite été rattaché à l'espèce $L$ maculans, les auteurs considérant qu'il s'agissait d'un variant de grande taille du type dans l'espèce (Smith et Sutton, 1964).

\section{CYCLE DE L MACULANS SUR COLZA D'HIVER, EN FRANCE}

Un rôle primordial dans le processus infectieux est attribué à la forme sexuée du champignon (Lacoste et al, 1969 ; Brunin, 1970 ; Brunin et Lacoste, 1970 ; McGee et Emmett, 1977). Après la récolte, le champignon se développe en saprophyte sur les résidus de cultures. Des croisements s'opèrent entre souches, le champignon fructifie et produit des périthèces. Les ascospores sont libérées pendant toute l'année, avec un pic d'émission à l'automne, période où le colza est le plus sensible à l'infection (Alabouvette et Brunin, 1970 ; Gladders et Musa, 1980). Les ascospores, qui peuvent être transportées par le vent sur plusieurs kilomètres, sont à l'origine de l'infection primaire de différentes parties aériennes des plantules, susceptible d'aboutir à tout un ensemble de symptômes lorsque les conditions thermiques, pluviométriques et hygrométriques sont favorables (Lacoste et al, 1969 ; Alabouvette et Brunin, 1970 ; Petrie, 1978).

Le champignon pénètre par les stomates ou des blessures (Brunin, 1970). Le parasite envahit ensuite les espaces intercellulaires dans le mésophylle du limbe, sans manifestation externe (Hammond et al, 1985). Dans un deuxième 
temps, les hyphes colonisent les tissus du limbe et le symptôme primaire de la maladie, la macule, se développe (fig 1a). Celle-ci porte des pycnides, dont les spores issues de la multiplication asexuée (conidies) peuvent être à l'origine d'infections secondaires ou d'une aggravation de l'infection primaire (Alabouvette et al, 1974). Le pouvoir de dispersion des conidies demeure néanmoins très limité par rapport à celui des ascospores (Lacoste et al, 1969). Une fois un vaisseau atteint, le mycélium se propage le long du pétiole, principalement dans les vaisseaux du xylème ou entre les cellules du parenchyme du xylème et du cortex pour atteindre la tige et s'y propager le long des tissus du cortex, sans provoquer de symptôme (Hammond et al, 1985). L'infection au champ se caractérise ainsi par une longue période de latence pouvant atteindre plusieurs mois (Nathaniels et Taylor, 1983 ; Xi et al, 1991a). Au terme de cette phase systémique biotrophe, $L$ maculans devient nécrotrophe et peut provoquer une nécrose au collet, phase ultime de l'infection (fig 1b). Sur colza comme sur d'autres crucifères sensibles, la nécrose du collet peut occasionner la verse de la plante dès la floraison et est susceptible d'entraîner de sérieuses pertes de rendement.

Les semences de colza peuvent être infectées par du mycélium ou des conidies et être la cause primaire d'introduction de $L$ maculans dans des régions vierges de maladie (Gabrielson, 1983 ; Humpherson-Jones, 1986). De même chez le chou, elles constituent potentiellement des sources primaires d'infection (Bonman et Gabrielson, 1981).

\section{LES SYMPTÔMES}

Plusieurs faciès de symptômes ont été décrits pour cette maladie dès 1849. Les plus courants sont les suivants :
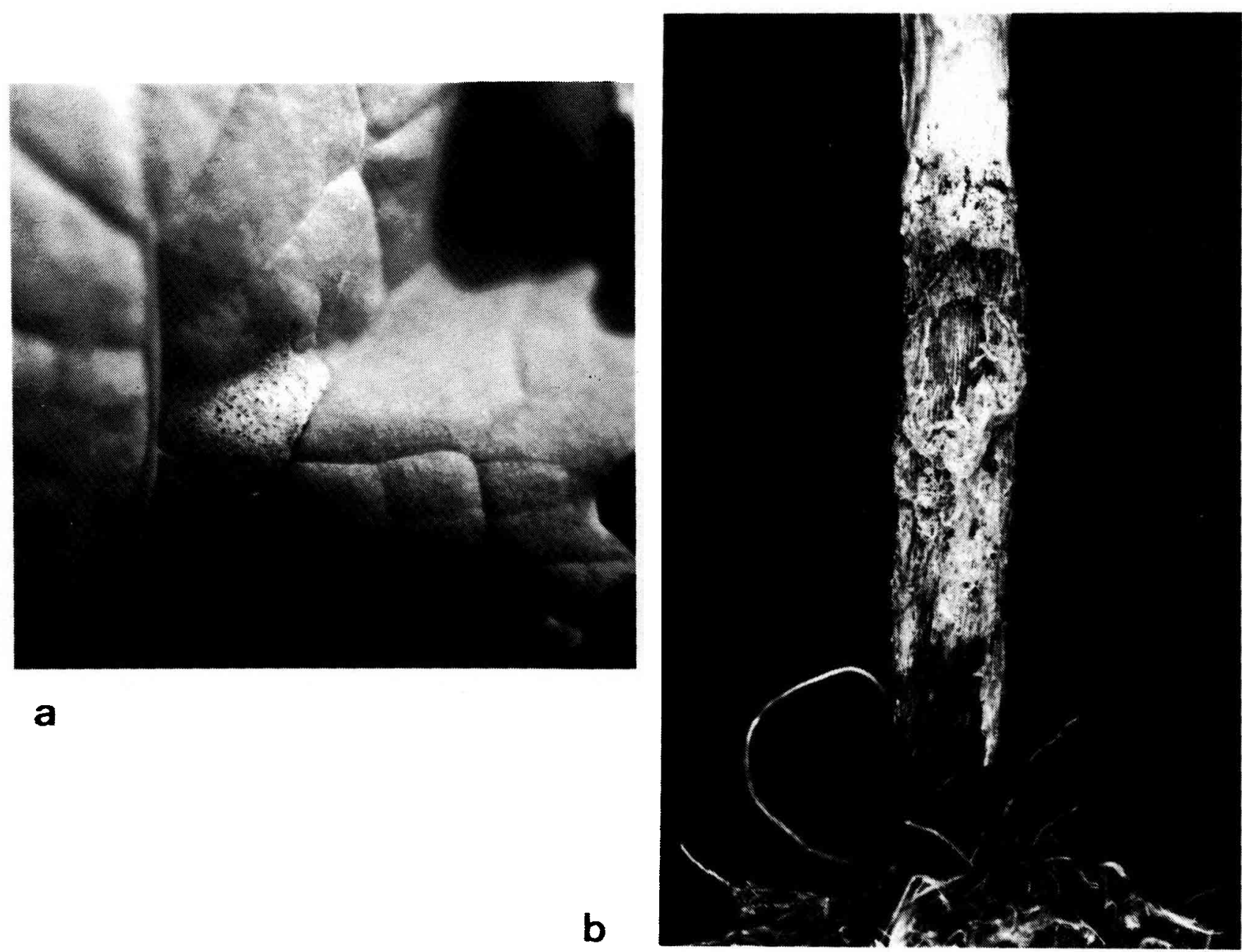

Fig 1. Les 2 symptômes typiques du «phoma du colza», obtenus en serre, après pulvérisation sur plantules d'une suspension de conidies. a. Le symptôme précoce (10 à 15 j après inoculation), la macule foliaire sur laquelle se différencient les pycnides. b. La nécrose du collet, développée 4 à 5 mois après inoculation, et présentant 2 faciès distincts : une nécrose noire caractéristique dans la partie basse et une nécrose plus sèche, chancreuse, dans la partie haute du collet. 
i) Sur organes aériens (cotylédons et feuilles, mais aussi tiges et siliques), des taches ou macules de 5 à $15 \mathrm{~mm}$ de diamètre, de couleur gris cendré (fig 1a). Ces macules deviennent fines et fragiles avec l'âge de la lésion. En conditions humides, les pycnides différenciées sur les macules libèrent des conidies visibles sous forme d'un cirrhe rose à rouge «sang de bœuf» (Brunin, 1970 ; Régnault et al, 1987). En conditions d'inoculation contrôlées, selon les organes, l'espèce attaquée et la souche responsable de l'attaque, la macule peut ne présenter aucune délimitation avec le tissu végétal ou être entourée d'une marge nécrotique sombre.

ii) Sur tige, une pourriture brune (blackleg), souvent accompagnée d'une lésion chancreuse plus sèche (canker), se développe au niveau du collet, provoque un étranglement responsable dans un premier temps d'une déficience alimentaire puis, dans un second temps, d'une éventuelle verse parasitaire (Lacoste et al, 1969) (fig 1b). On observe généralement la présence de pycnides sur les tissus nécrosés. Plusieurs autres types de symptômes ont été associés à cette maladie, différant des symptômes typiques en fonction de critères peu compris (espèce cultivée, conditions climatiques, type de souche ?).

iii) Une nécrose sèche de la tige (dry-rot des anglo-saxons) a été décrite sur certaines espèces (rutabaga), dans certaines conditions de température (entre 15 et $24^{\circ} \mathrm{C}$ ), ou dans des conditions physiologiques particulières liées à la conservation des produits de la récolte (Cunningham, 1927 ; Hill, 1992). Les taches formées s'étendent en surface et en profondeur au voisinage du sol. Elles entourent peu à peu totalement la tige qui prend une teinte grisâtre. Des pycnides se différencient sur les zones nécrotiques et l'atteinte de la tige peut aussi conduire à une verse parasitaire.

iv) Sur chou, une extension de la nécrose de la tige aux racines a été décrite (Henderson, 1918). L'atteinte de ces dernières est telle que les racines latérales, voire le pivot, sont totalement détruits. La maladie se traduit alors par un flétrissement des plantes plutôt que par une verse. $\mathrm{Ce}$ symptôme est apparenté aux symptômes typiques du "pied sec", récemment décrits en France sur colza et entraînant un dessèchement prématuré de la plante (Brun et Jacques, 1990).

v) Notons enfin qu'une attaque très précoce peut se traduire par une fonte des semis (Henderson, 1918 ; Petrie, 1969).

Le polymorphisme des symptômes est bien traduit par la multitude de termes anglais se rap- portant à cette maladie tels que : "blackleg", "dry not", "premature ripening", "stem canker", "damping off», "premature splitting of pods" ou "root rot". Le seul point commun entre ces différents symptômes n'est souvent que le développement de pycnides sur les tissus nécrosés. Finalement cette diversité des symptômes observés pourrait être due à de multiples causes telles que l'espèce infectée, le stade végétatif considéré, les conditions climatiques ou de culture, etc, tout comme il pourrait être lié à des attaques par différents types de souches.

\section{LES PLANTES-HÔTES}

La forme imparfaite du parasite a été isolée de nombreuses Brassica ou autres crucifères cultivées (Sinapis alba, Raphanus sp, etc), ainsi que de crucifères adventices (Sinapis arvensis $L$, Armoracia lapathifolia Gilib, Cheiranthus cheiri L, Iberis umbellata $\mathrm{L}$, Matthiola incana $\mathrm{R} \mathrm{Br}$, Raphanus raphanistrum $\mathrm{L}$, Alyssum maritimum $\mathrm{L}$, etc) (pour une revue : Petrie, 1969 ; Hall, 1992). Sutton (1980) note aussi, entre autres, Beta vulgaris, Clematis $\mathrm{sp}$, Ficus palmata, ou Chrysanthemum sp comme plantes-hôte de $P$ lingam ! II est possible que la complexité du genre Phoma et le flou des critères utilisés pour différencier les espèces de ce genre (souvent, seules de mineures différences morphologiques, ou l'hôte sur lequel le champignon a été isolé sont pris en compte pour définir l'espèce) soient responsables d'une gamme d'hôte aussi large. Ainsi, il est probable que des Phoma très différents aient été assimilés à $P$ lingam sur la base de critères morphologiques peu fiables au vu de l'intense variabilité morphologique de $P$ lingam (cf plus loin). On ne peut donc qu'être très prudent à ce stade en ce qui concerne la gamme d'hôtes de $P$ lingam.

Les périthèces de $L$ maculans ont été observés sur les tiges de nombreuses crucifères (Brassica sp, Arabis arenosa Scop, Isatis tinctoria $\mathrm{L}$, Erysimum $\mathrm{sp}$, Lepidium virginicum $\mathrm{L}, \ldots$ ), mais aussi de plantes appartenant à des familles différentes telles que l'épilobe (Epilobium angustifolium L, fam Onagraceae), le houblon (Humulus L, fam Cannabidacea), la germandrée (Teucrium sp, fam Labiatae), Swertia perennis (fam Gentianaceae) ou Phaseolus sp (fam Leguminosae) (pour une revue: Petrie, 1969). Les travaux concernant le houblon, Phaseolus $\mathrm{sp}$, ou Teucrium $\mathrm{sp}$ datent de la seconde moitié du $\mathrm{XIX}^{\mathrm{e}}$ siècle et n'ont jamais été confirmés. On peut donc supposer que les crucifères adven- 
tices et cultivées sont les hôtes principaux, voire exclusifs de ce parasite.

Selon Petrie (1969), les souches canadiennes (Saskatchewan) du parasite peuvent être regroupées en 5 groupes en fonction de l'espèce de crucifère dont elles proviennent et de leur gamme d'hôte. Les 3 groupes principaux (en fréquence) sont les groupes «Brassica» (isolé de Brassica sp mais aussi d'autres crucifères cultivées telles que $S$ alba ou $R$ sativus), «Sysimbrium» (isolé de plusieurs espèces de Sysimbrium, mais aussi de Descurainia sophia et de diverses crucifères cultivées), et "Thlaspi» (isolé de Thlaspi arvense $\mathrm{L}$ mais aussi de $B$ napus et $D$ sophia). Deux autres groupes, plus anecdotiques en ce sens qu'ils ne concernent qu'un nombre très limité de souches, ont aussi été décrits : le groupe "Lepidium", isolé de Lepidium sp et le groupe "Descurainia", isolé de Descurainia richardsonii.

\section{POLYMORPHISME DU PARASITE}

Dès 1849, Desmazière note qu'«il est peu d'espèces du genre qui soient aussi polymorphes». Cunningham (1927), puis Pound (1947) rapportent des variations majeures entre souches isolées de Brassica sp en examinant leur pouvoir pathogène et diverses caractéristiques culturales. Jusqu'à la fin des années 1980, seuls des critères pathologiques ou morphologiques ont été utilisés. Ceux-ci corroboraient les résultats de Cunningham ou de Pound, et concluaient globalement à l'existence de 2 types de souches «Brassica»: i) peu pathogènes et à croissance rapide et ii) pathogènes et à croissance lente. Les variations observées dans chaque groupe ou les exceptions à cette règle étaient alors, et de nouveau, attribuées au polymorphisme exceptionnel de cet agent pathogène. Mais ce n'est qu'avec le développement récent d'analyses biochimiques et moléculaires plus performantes que la complexité du pathosystème est réellement apparue.

\section{Les méthodes classiques d'évaluation du polymorphisme : 2 groupes de souches sur Brassica sp}

\section{Critères morphologiques et culturaux}

Classiquement, la morphologie des spores et des organes de reproduction et l'aspect de la culture in vitro ont été tout d'abord analysés. Plus récemment, la vitesse d'élongation des tubes germinatifs des conidies a été considérée.

L'analyse d'une collection d'isolats selon la taille et la morphologie des conidies et pycnides a surtout été développée par Pound (1947) et Petrie (1969). Pound compare des souches isolées de chou ( $B$ oleracea), de chou chinois ( $B$ rapa) ou d'Alyssum maritimum et provenant de diverses régions des États-Unis. Petrie analyse principalement des souches du Saskatchewan en fonction de la plante-hôte dont elles proviennent : souches "Brassica", souches "Sysimbrium", souches "Thlaspi», souches "Lepidium" ou souches "Descurainia" (cf plus haut). Dans les 2 cas, si des différences de taille entre conidies des diverses souches sont observées, les auteurs notent que ces variations restent dans la gamme communément admise pour ce parasite (conidies cylindriques, monocellulaires, uninuclées, hyalines, de 3 à $5,5 \mu \mathrm{m}$ de longueur et de 1,5 à $2 \mu \mathrm{m}$ de largeur) (fig 2a). II existe toutefois une exception: les souches «Descurainia» isolées par Petrie présentent des conidies de taille supérieure à celles des souches des autres groupes $(4,4$ à $11 \mu \mathrm{m}$ de longueur et de 1,5 à $4,4 \mu \mathrm{m}$ de largeur) (fig 2a). Par ailleurs, l'intense polymorphisme de taille et de forme des pycnides, observé aussi bien au champ qu'en culture pour une souche donnée, ne permet pas de discrimination claire entre souches.

Petrie (1969) a aussi comparé la morphologie des périthèces, asques et ascospores des 5 groupes de souches du Saskatchewan. Aucune différence morphologique entre souches n'est mise en évidence en ce qui concerne tant la morphologie que la structure des ascocarpes et des asques. Enfin, les ascospores sont toutes de forme semblable (fusoïde), majoritairement à 6 cellules séparées par 5 septa (fig $2 b$ ), avec une constriction plus prononcée au niveau du septum central. Tous les groupes présentent des ascospores dont la taille moyenne est dans la gamme admise pour cette espèce : 30 à $80 \mu \mathrm{m}$ de longueur et 5 à $11 \mu \mathrm{m}$ de largeur (fig 2c). Toutefois, des souches «Descurainia» présentent une distribution des tailles des ascospores décalée par rapport aux autres groupes (fig $2 \mathrm{c}$ ).

Sur la base de l'aspect des cultures in vitro, Cunningham (1927) puis Pound (1947) distinguent 2 groupes principaux de souches "Brassica». Le premier est caractérisé par un faible développement de mycélium aérien, une croissance lente, et une production abondante de pycnides. Le second groupe, beaucoup plus polymorphe que le premier en ce qui concerne la 

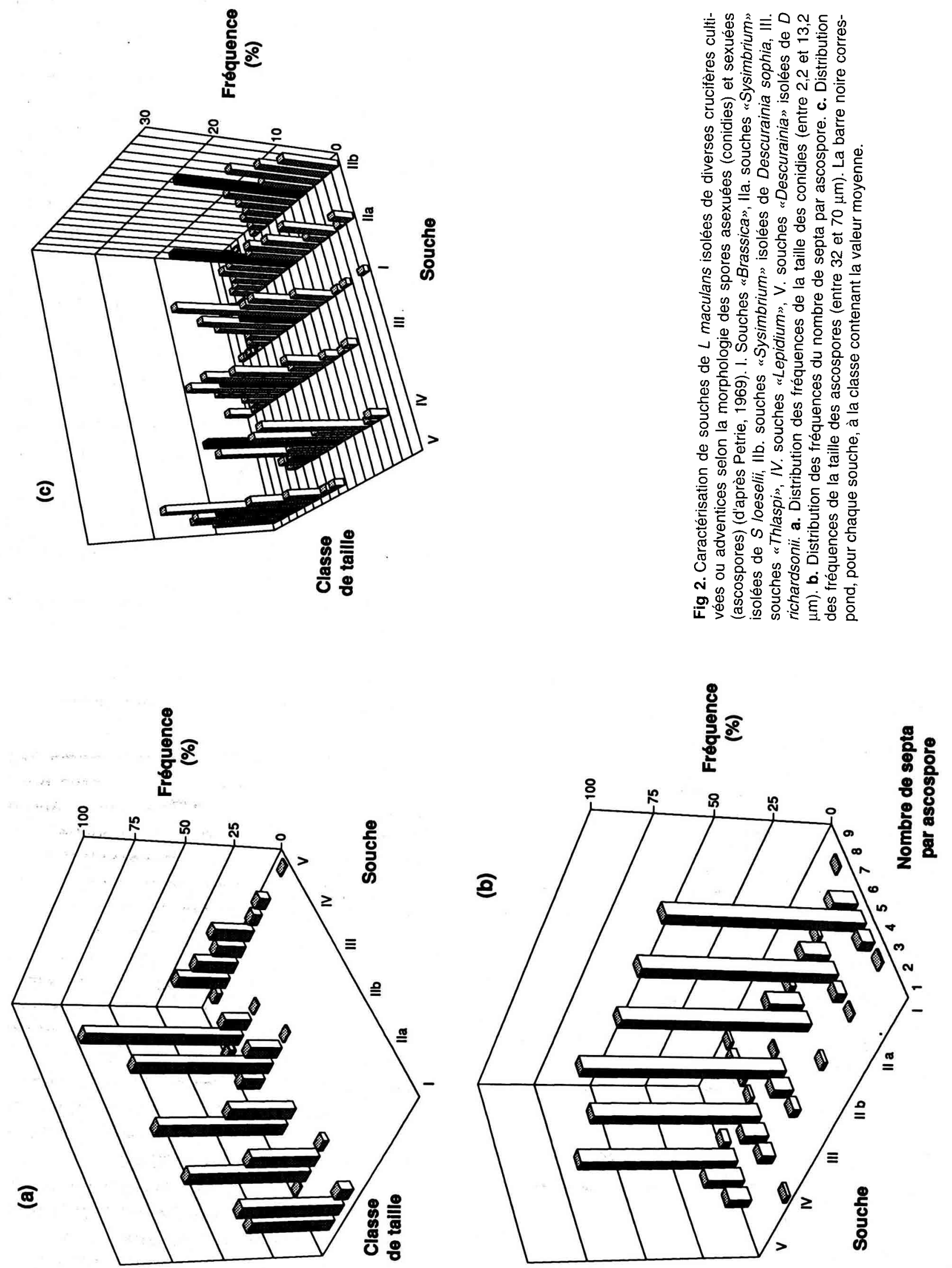
couleur du mycélium, la production de pigments ou la sporulation, est caractérisé par une production abondante de mycélium aérien et une croissance rapide, souvent accompagnée d'une faible production de pycnides. Les 2 types de souches pouvaient être obtenus à partir d'un unique isolat (Pound, 1947). Les travaux de Pound jettent un doute supplémentaire sur la validité de ce critère morphologique puisque l'auteur observe chez les 2 types de souches des sectorisations donnant naissance à des colonies stables du type morphologique opposé à celui de la colonie originelle. Ce même type de résultat a été obtenu dans nos conditions de culture où des clones monoconidiens issus d'une souche monoascosporée présentent des sectorisations intenses ou des variations morphologiques stables (fig 3). Par exemple, l'un des variants est caractérisé par une forte production de pycnides et un mycélium ras alors qu'un autre variant présente une sporulation rare et un mycélium aérien abondant (fig 3). Par ailleurs Pound (1947) distingue 2 types de souches à croissance rapide : des souches produisant un abondant mycélium blanc ou gris clair et des souches produisant sur différents milieux de culture un pigment soluble jaune à brun, dont le mycélium lui-même finit par être pigmenté. Ces dernières souches isolées de chou ou de navette dans l'état de Washington (souches "Puget Sound») étaient similaires à des souches isolées d'Alyssum maritimum en Californie.

Des résultats identiques, distinguant 2 groupes de souches en fonction de leur vitesse de croissance et/ou leur production de pycnides in vitro, ont été obtenus par Delwiche (1980), Humpherson-Jones (1986), Koch et al (1989) ou Gall (1994). Delwiche (1980) souligne toutefois que de telles différences de croissance sont très dépendantes des conditions de culture et qu'elles peuvent être abolies, à certaines températures par exemple. De la même façon, la production de pigments in vitro est décrite par de nombreux auteurs pour une distinction des 2 types de souches (McGee et Petrie, 1978 ; Delwiche, 1980 ; Bonman et Gabrielson, 1981 ; Humpherson-Jones, 1983 ; Koch et al, 1989 ; Balesdent et al, 1992). McGee et Petrie (1978) montrent que les souches "Thlaspi" se rattachent par leurs caractéristiques culturales (vitesse de croissance et production de pigment) aux souches de type "Puget Sound". Ces mêmes auteurs soulignent le peu de validité du critère "production de pycnides" in vitro pour une différenciation des souches. Si plusieurs auteurs soulignent une bonne corrélation entre production de pigments in vitro et rapidité de croissance (par exemple : McGee et Petrie, 1978), d'autres auteurs sont plus prudents, à commencer par Pound (1947) qui observe des souches à croissance rapide aussi bien chez les producteurs que chez les non producteurs de pigments. Delwiche (1980) souligne une excellente corrélation entre production de pigment et vitesse de croissance chez 50 souches européennes analysées. En revanche, cette corrélation s'avère beaucoup moins claire pour les 53 souches iso-

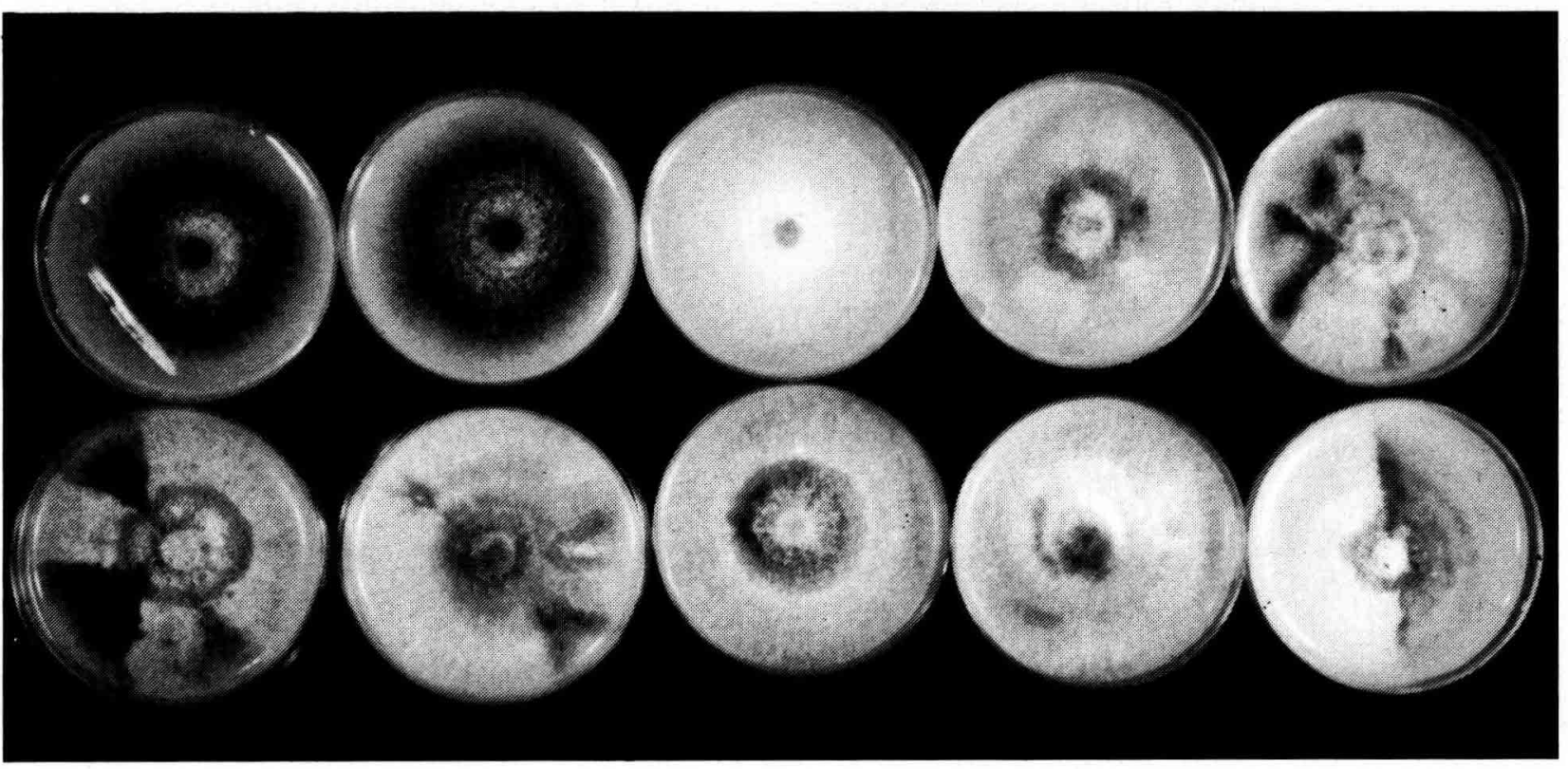

Fig 3. Variabilité morphologique de $L$ maculans en culture. Les 10 boîtes correspondent à 10 clones monoconidiens issus de la même souche monoascosporée. Quatre clones présentent des sectorisations abondantes. Deux clones (à gauche, rangée supérieure) présentent une variation morphologique stable, caractérisée par un mycélium ras et par la formation de très nombreuses pycnides. Les souches ont été cultivées sur milieu V8-gélosé, à $20^{\circ} \mathrm{C}$ pendant $20 \mathrm{j}$. 
lées de chou dans le Wisconsin, puisque 8 des 35 souches à croissance rapide ne produisaient pas de pigments. De même, nos propres travaux portant sur un nombre limité de souches monoascosporées françaises montrent une certaine indépendance entre croissance et production de pigments. Ainsi, si des souches à croissance rapide peuvent être statistiquement différenciées de souches à croissance plus lente, on peut noter la présence d'une souche productrice de pigments parmi les souches à croissance lente et de 2 souches non productrices de pigments parmi les souches à croissance rapide (Gall, 1994). Surtout, la production de pigments en milieu synthétique reste très variable, pour une même souche, d'une répétition à l'autre (Balesdent et al, 1992).

Petrie (1988) propose enfin une distinction des types de souches sur la base de la vitesse d'élongation des tubes germinatifs issus des conidies. Ainsi, après 40 à $44 \mathrm{~h}$ de germination sur eau gélosée, l'auteur constate une croissance beaucoup plus rapide des tubes germinatifs des souches de type "Puget Sound" par rapport aux autres souches "Brassica". L'analyse d'une souche "Thlaspi" met en évidence une croissance intermédiaire entre celles des 2 types précédents.

\section{Pouvoir pathogène}

Sur Brassica, 2 types de souches différant par leur pouvoir pathogène ont été décrits. Selon les auteurs, ces 2 groupes sont appelés "weakly parasitic" et "strongly parasitic" (Cunningham, 1927), "virulent" (ou "highly virulent") et "slightly virulent» (Pound, 1947), "virulent" et "avirulent» (McGee et Petrie, 1978), "weakly pathoge- nic» et "strongly pathogenic» (Delwiche, 1980), "virulent" et "non-virulent" (Humpherson-Jones, 1983), "aggressive" et "non-aggressive" (Koch et al, 1989). Classiquement, après inoculation sur tissus foliaires de Brassica sp, les souches "pathogènes" causent les macules grisâtres typiques, alors que les souches "faiblement pathogènes" causent des lésions plus brunes, qui apparaissent plus rapidement que les macules, mais se développent plus lentement (Delwiche, 1980). Au Canada, la capacité des souches "faiblement pathogènes" à causer la nécrose du collet au champ est considérée comme très faible (Gugel et Petrie, 1992).

Le pouvoir pathogène, sur plantules in vitro, des différents groupes de souches isolées par Petrie de Brassica ou de crucifères adventices est résumé dans le tableau I (Petrie, 1969).

Dès 1927 , il est établi qu'il existe une étroite corrélation entre caractéristiques culturales (production de pigments et taux de croissance) et pouvoir pathogène des souches isolées de Brassica sp (Cunningham, 1927). Même si des précautions sont prises par la plupart des auteurs, le dogme "souches pathogènes sur Brassica, à croissance lente et non productrices de pigments en milieu de culture" contre "souches faiblement pathogènes sur Brassica, à croissance rapide et productrices de pigments en milieu de culture" (type "Puget Sound") a peu été remis en question depuis lors (par exemple : McGee et Petrie, 1978 ; Koch et al, 1989). Curieusement, Humpherson-Jones (1983) corrèle aux 2 «pathotypes» des caractéristiques culturales très différentes de celles décrites par les autres auteurs. Cet auteur compare le pouvoir pathogène et les caractéristiques culturales de plus de 1800 souches britanniques sur un milieu

Tableau I. Interaction des souches des groupes "Brassica", "Sysimbrium», "Thlaspi», "Lepidium» et "Descurainia» avec diverses crucifères cultivées ou adventices (d'après Petrie, 1969).

Type de souche

Brassica $s p$

Thlaspi $s p$

Plantes hôtes

$\begin{array}{ll}\text { "Brassica» } & \mathrm{S} \\ \text { "Sysimbrium" } & \mathrm{S} \\ \text { "Thlaspi» } & \mathrm{S} \\ \text { "Lepidium" } & \mathrm{S} \\ \text { "Descurainia" } & \mathrm{R}\end{array}$

$S$ : sensibilité ; $R$ : résistance.

\section{Lepidium $s p \quad$ Descurainia $s p \quad$ Camelina $s p$}

$\begin{array}{llll}R & S & R & R \\ S & S & S & S \\ S & S & S & R \\ R & S & S & S \\ R & S & S & R\end{array}$

R

$S$

R

R 
de culture, le "prune lactose agar», différent de ceux qui sont les plus couramment utilisés, tels que V8 gélosé ou malt gélosé. L'auteur conclut de son étude qu'une sporulation abondante et un mycélium ras caractérisent les souches «faiblement pathogènes», alors que les souches «pathogènes» produisent un mycélium aérien, pouvant être pigmenté de jaune, orange ou brun, et une faible quantité de pycnides. La validité de ces corrélations et, en particulier, la fiabilité des critères culturaux pour différencier les 2 groupes de souches ont en outre été discutées à quelques reprises. Ainsi, même si, dans la plupart des cas, la vitesse de croissance moyenne in vitro est supérieure chez les souches «faiblement pathogènes", il existe de nombreux chevauchements (souches «faiblement pathogènes" à vitesse de croissance similaire à celle des souches «pathogènes» et vice-versa) qui rendent ce critère inutilisable pour une différenciation fiable des groupes de souche (Delwiche, 1980 ; Gall, 1994). De la même manière, des souches «faiblement pathogènes" non productrices de pigments, voire, plus rarement, des souches "pathogènes» productrices de pigments, sont parfois décrites (Delwiche, 1980 ; Johnson et Lewis, 1990 ; Balesdent et al, 1992).

La fiabilité des données concernant le pouvoir pathogène a elle-même été remise en cause à quelques reprises. Pour identifier les phénotypes d'interaction sur plantules, un test d'inoculation sur cotylédons en conditions contrôlées est largement utilisé (Williams et Delwiche, 1979). Suivant ce test, les souches «faiblement pathogènes" déclenchent habituellement des réactions hypersensibles, ou des symptômes ressemblant à des taches nécrotiques irrégulièrement réparties autour du point d'inoculation et qui peuvent devenir coalescentes (Koch et al, 1989, 1991 ; Badawy et al, 1991 ; Mengistu et al, 1991). À température élevée $\left(27^{\circ} \mathrm{C}\right)$, Badawy et al (1992) observent des lésions plus grandes, proches de celles causées par les souches «pathogènes», mais demeurant en partie nécrotiques. En utilisant la même technique d'inoculation et, pour référence, 3 des souches analysées par Koch et al (1991), des résultats très différents de ceux qui ont été publiés par cette dernière équipe ont été obtenus à Versailles (Gall et al, 1994a). Ainsi, la confrontation de 12 souches «faiblement pathogènes» et «pathogènes»sur une gamme de crucifères permet de distinguer 3 groupes de souches (tableau II) : i) des souches dont la gamme d'hôte est limitée à 3 espèces de Brassica : $B$ napus, $B$ rapa et $B$ oleracea, sur les cotylédons desquelles elles causent des symptômes typiques. Ces 3 souches ne produisent pas de pigment in vitro (Balesdent et al, 1992) et sont assimilées par l'ensemble de leurs caractéristiques aux souches «pathogènes" ; ii) une

Tableau II. Interaction entre souches Tox ${ }^{+}$ou Tox ${ }^{0}$ de $L$ maculans et diverses crucifères (d'après Gall et al, 1994a).

$\begin{array}{ccccc}\text { G2 } & \text { Tox }^{0} & \text { Tox }^{0} & \text { Tox }^{0} & \text { Tox }^{+} \\ (\text {Tox } & (\text { groupe NA1) } & (\text { groupe NA2) } & \text { (groupe NA3) } & \end{array}$

\begin{tabular}{|c|c|c|c|c|c|}
\hline$B$ napus cv Westar & $\mathrm{R}$ & $S$ & $S$ & $S$ & $S$ \\
\hline$B$ napus cv Samourai & $\mathbf{R}$ & $S$ & S & $S$ & $S$ \\
\hline B carinata cv Awassa 67 & na & $\mathrm{S}$ & $\mathrm{S}$ & 1 & $\mathrm{R}$ \\
\hline B juncea cv Aurea & $\mathrm{R}$ & $S$ & $S$ & $S$ & $R$ \\
\hline$B$ nigra $\mathrm{cv}$ Junius & $\mathbf{R}$ & $\mathrm{S}$ & $\mathrm{S}$ & $\mathrm{S}$ & R \\
\hline$B$ oleracea cv Europ & na & $\mathrm{S}$ & $S$ & $\mathrm{~S}$ & $\mathrm{~S}$ \\
\hline$B$ rapa cv Matsushimajun & na & $S$ & $S$ & $S$ & $\mathrm{I}-\mathrm{S}$ \\
\hline$B$ adpressa a & $\mathrm{R}$ & $\mathrm{S}$ & $\mathrm{S}$ & R-I & $\mathrm{R}$ \\
\hline Raphanus raphanistrum ${ }^{a}$ & na & I-S & $\mathrm{S}$ & I & $\mathrm{R}$ \\
\hline Raphanus sativus cv Pegletta & na & $\mathrm{S}$ & $S$ & $S$ & $\mathbf{R}$ \\
\hline Sinapis alba cv Emergo & $\mathrm{R}$ & 1 & $\mathrm{~S}$ & $\mathrm{R}$ & I \\
\hline Sinapis vesicatoria a & $\mathrm{R}$ & 1 & $S$ & 1 & $\mathrm{R}$ \\
\hline
\end{tabular}

La réponse des plantes est évaluée selon un test d'inoculation sur cotylédons, en conditions d'incubation contrôlées. $R$ : résistance ; $\mathrm{S}$ : sensibilité ; $\mathrm{I}$ : réaction intermédiaire; na : non analysé. a $B$ adpressa, Raphanus raphanistrum et Sinapis vesicatoria sont des populations issues de plantes sauvages récoltées en France. 
souche typique du groupe «faiblement pathogène", productrice de pigment in vitro et induisant une résistance hypersensible sur toutes les espèces de crucifères analysées ; iii) toutes les autres souches présentent les caractéristiques culturales des souches du groupe ufaiblement pathogène" et/ou sont classées dans ce groupe par Koch et al (1991). Toutefois, ces souches sont capables de causer des macules sur les cotylédons de toutes les crucifères analysées. Ces macules conservent un caractère plus nécrotique que celles causées par les souches "pathogènes», mais elles apparaissent beaucoup plus tôt ( $7 \mathrm{j}$ après inoculation, contre $12 \mathrm{j}$ pour les souches "pathogènes") et le développement du symptôme s'accompagne souvent de chloroses importantes du cotylédon. Parmi ces souches "faiblement pathogènes", 4 souches polonaises sont considérées comme représentatives de populations causant la nécrose du collet du colza en Pologne. Par ailleurs, une analyse comparative de leur pouvoir pathogène sur le cutivar de colza Lirakus montre que ces souches "faiblement pathogènes" causent des symptômes plus sévères que 2 souches françaises représentatives du groupe "pathogène» (Golinski, communication personnelle).

Ces données sont compliquées par l'existence d'interactions spécifiques de type souche-cultivar chez les souches "pathogènes". Ainsi, certaines souches "pathogènes" sont avirulentes sur un certain nombre de cultivars de colza (Badawy et al, 1991 ; Mengistu et al, 1991). Les réactions de résistance provoquées lors de telles interactions, en particulier lors de la confrontation d'une souche avirulente avec le cultivar Quinta, sont identiques à la réaction du colza aux souches "faiblement pathogènes". Dans ces conditions, il semble difficile d'utiliser l'aspect du symptôme induit lors de l'inoculation pour une reconnaissance fiable des souches du groupe «faiblement pathogène». Ceci est d'autant plus vrai qu'il a aussi été décrit des souches «pathogènes» induisant des résistances hypersensibles chez la plupart des cultivars de colza sur lesquels elles ont été inoculées (Hassan et al, 1991 ; Gall, 1994).

Les travaux de Gugel et al (1990) vont plus loin dans la critique de l'interprétation des symptômes et jettent un doute sérieux sur la validité de la réaction hypersensible initiale en tant que représentative d'une résistance. Suivant un test sur cotylédons, les auteurs observent aussi une restriction de la gamme d'hôte à $B$ napus, $B$ oleracea et $B$ rapa pour les souches "pathogènes». Les souches "faiblement pathogènes" causent des lésions similaires sur toutes les Brassica, moins intenses que celles provoquées par les souches "pathogènes". Mais, 7 sem après inoculation, et quel que soit le symptôme initialement exprimé sur cotylédon (macule sporulante ou réaction nécrotique), les souches inoculées sont réisolées à la base de la tige, voire dans les racines chez un pourcentage parfois important de plantes. Ainsi une souche "pathogène" pouvait être réisolée de $39 \%$ des plantes d'une lignée de moutarde noire ( $B$ nigra) ayant exprimé sur cotylédons une réaction hypersensible. Cette valeur n'était pas sensiblement différente de celle obtenue pour 3 des Brassica ayant exprimé sur cotylédons une forte sensibilité. Une autre souche "pathogène" était réisolée, selon les cultivars, de 25 à $61 \%$ des moutardes ( $B$ juncea, $B$ nigra ou $B$ carinata) ayant exprimé un fort niveau de résistance cotylédonnaire. Enfin, en fonction des expériences considérées, la souche «faiblement pathogène" était réisolée de 29 à $75 \%$ des plantes ayant exprimé à l'origine une résistance ou un symptôme modéré sur cotylédons.

L'ensemble de ces données suggère que le pouvoir pathogène, comme les caractéristiques culturales, n'est pas un critère totalement fiable pour une différenciation des types de souches puisque, selon les souches utilisées, la gamme d'espèces ou de cultivars analysée, les protocoles de préparation de l'inoculum, d'inoculation ou d'incubation des plantes, des différences majeures peuvent survenir dans l'expression des symptômes.

\section{Production de toxines}

Les premiers composés phytotoxiques mis en évidence et caractérisés à partir de filtrats de culture d'isolats de $P$ lingam ont été la sirodesmine PL et 2 dérivés (Férézou et al, 1977 ; Poiret et al, 1985). De nombreuses autres sirodesmines ont ensuite été isolées (Pedras et al, 1988 ; 1990 ; Badawy et Hoppe, 1989), la sirodesmine PL restant le composé majoritairement produit in vitro. Par ailleurs, un composé à propriétés antibiotiques et antifongiques, l'acide phoménoïque, a été extrait des parois du parasite en culture (Devys et al, 1984 ; Balesdent et al, 1992). Si l'implication de ces divers composés dans le pouvoir pathogène du parasite reste prospective (Boudart, 1978 ; Koch et al, 1989 ; Rouxel et al, $1988,1994)$, l'analyse par chromatographie en couche mince (CCM) de 352 souches monoascosporées a permis une différenciation des souches en 2 groupes : les souches productrices 
de sirodesmines, correspondant à des souches "agressives" sur Brassica et non productrices de pigments en milieu de culture, et les souches non productrices de sirodesmines, correspondant à des souches "non agressives» sur Brassica et productrices de pigments en milieu de culture (Koch et al, 1989). Malgré une production de pigments inconstante, une telle corrélation a été retrouvée lors de l'analyse par chromatographie liquide à haute performance (CLHP) de la production d'acide phoménoïque et de sirodesmine PL d'une collection de souches françaises (Balesdent et al, 1992). Enfin, l'absence de production de sirodesmines chez 4 souches "Thlaspi" a aussi été démontrée (Pedras et al, 1990).

Par rapport à la croissance, à la production de pigments, ou même au pouvoir pathogène, l'analyse de la production de ces toxines donne, pour une souche donnée, des résultats fiables et qualitativement invariables permettant une discrimination absolue en 2 groupes. De même, la production d'acide phoménoïque est le seul critère qui est absolument corrélé avec la production de sirodesmines in vitro. Ainsi le pouvoir pathogène, en particulier dans le cas de souches avirulentes sur une gamme de cultivars, peut dépendre du type d'interaction considéré. On peut aussi rappeler à ce sujet que des mutants "hypovirulents" sur chou, mais producteurs de toxines, ont été obtenus par Boudart (1978). Du fait de la plus grande fiabilité de la production de toxines pour une discrimination des 2 groupes de souches, nous adoptons pour la suite de cet article la terminologie souches $\mathrm{Tox}^{+}$(équivalent des souches "Brassica" "pathogènes" ou des souches agressives, ou virulentes d'autres auteurs) et souches Tox ${ }^{0}$ (équivalent des souches "Brassica" "faiblement pathogènes" ou des souches "Puget Sound" de Pound, ou nonagressives, ou non-virulentes d'autres auteurs) (Gall et al, 1994a).

En revanche, l'analyse par CLHP de la production in vitro de la sirodesmine PL donne des résultats quantitatifs fluctuants pour une souche donnée (Gall, 1994). Une telle analyse ne permet donc pas d'examiner un quelconque polymorphisme au sein du groupe Tox $^{+}$. À plus forte raison, de telles analyses ne permettent aucune caractérisation à l'intérieur du groupe des Tox ${ }^{0}$.

\section{Compatibilité sexuelle}

$L$ maculans est un champignon hétérothallique, dont la compatibilité sexuelle est contrôlée par 2 allèles d'un même locus (Venn, 1979 ; Boudart,
1981 ; Gall et al, 1994b). La mise au point récente de méthodologies permettant l'obtention reproductible et systématique de croisements fertiles sur milieu de culture fournit la possibilité de déterminer l'aptitude des souches à se croiser (Mengistu et al, 1993 ; Gall et al, 1994b). Dans ces conditions, seule la confrontation 2 à 2 des souches $\mathrm{Tox}^{+}$est susceptible de conduire à la formation de périthèces matures (Delwiche, 1980 ; Petrie et Lewis, 1985 ; Mengistu et al, 1993 ; Gall, 1994). Aucun croisement fertile n'a été obtenu lorsque des souches Tox ${ }^{0}$ sont confrontées entre elles ou à des souches Tox ${ }^{+}$ (Delwiche, 1980 ; Petrie et Lewis, 1985 ; Gall, 1994). De même, des croisements entre souches "Thlaspi» n'ont permis l'obtention que de périthèces ne contenant pas d'asques (Petrie et Lewis, 1985). Au vu de la complexité des conditions de culture permettant l'obtention de croisements fertiles dans le genre Leptosphaeria (Lacoste, 1965), on peut suggérer que les conditions les plus favorables au croisement de ces souches in vitro n'ont pas encore été définies.

\section{Les méthodes "modernes": proximité des souches et discrimination de sous-groupes}

Malgré la multiplication des méthodes utilisées, l'objectif de la plupart des travaux récents reste la différenciation des 2 "pathotypes" en comparant quelques souches appartenant à chacun des 2 groupes. Les études de profils de protéines de paroi (Hassan et al, 1991), ou de protéines mycéliennes solubles (Balesdent et al, 1992), les profils de polygalacturonidases (Annis et Goodwin, 1993), les analyses isoenzymatiques (Hill et al, 1984 ; Sippell et al, 1988 ; Annis et Goodwin, 1991 ; Gall et al, 1994a), les analyses RFLP (Johnson et Lewis, 1990 ; Koch et al, 1991 ; Hassan et al, 1991 ; Plummer et al, 1994), les RAPD (Goodwin et Annis, 1991 ; Schäfer et Wöstemeyer, 1992 ; Plummer et al, 1994), le "DNA fingerprinting" (Meyer et al, 1992), la mise en évidence d'ADN "plasmidlike" (Hassan et al, 1991), le séquençage des ITS (Morales et al, 1993a) ou l'analyse des caryotypes après électrophorèse en champ pulsé (Taylor et al, 1991 ; Plummer et Howlett, 1993 ; Morales et al, 1993b) concourent tous à cette séparation en 2 groupes. De plus, malgré le petit nombre de souches souvent analysé, les auteurs concluent généralement à un polymorphisme plus important au sein du groupe Tox ${ }^{0}$ par rapport au groupe Tox ${ }^{+}$. 
Analyses moléculaires : évaluation de la proximité taxonomique

L'analyse RFLP de 21 isolats britanniques montre une séparation en 2 groupes pouvant être davantage assimilés aux groupes déterminés par les caractéristiques culturales que par les critères pathologiques (Johnson et Lewis, 1990). De plus, les auteurs concluent à une plus grande variabilité au sein des souches non productrices de pigments par rapport aux 7 souches productrices de pigments. Parmi 15 souches canadiennes, Goodwin et Annis (1991) discriminent également 2 groupes de souches par analyse RAPD et concluent à une plus grande diversité au sein du groupe Tox ${ }^{0}$. Une telle diversité est attribuée à des isolements géographiques et à une présence plus ancienne de ces souches sur le continent américain, ayant favorisé des évolutions divergentes. Des résultats similaires, concernant à la fois une séparation en 2 groupes et une plus grande diversité au sein des Tox $^{0}$, sont obtenus sur une collection de 16 souches isolées en Allemagne, après analyses RAPD, RFLP, "DNA fingerprinting", ou de recherche et de caractérisation de "plasmid-like DNA» (Hassan et al, 1991 ; Meyer et al, 1992 ; Schäfer et Wöstemeyer, 1992). L'analyse d'une douzaine de souches australiennes par électrophorèse en champ pulsé, RFLP ou RAPD, montre des différences majeures entre isolats des 2 groupes (Plummer et al, 1994). Les électrocaryotypes et profils RFLP des souches «pathogènes» australiennes sont similaires à ceux des souches Tox ${ }^{+}$décrits par d'autres équipes. À l'opposé, des différences majeures sont observées entre les souches "faiblement pathogènes" isolées en Australie et les Tox ${ }^{0}$ analysées par ailleurs (Plummer et al, 1994). Enfin, l'ensemble des analyses par électrophorèse en champ pulsé effectuées au Canada ou en Australie confirme qu'il existe des différences majeures dans la taille des chromosomes entre les 2 groupes de souches.

Morales et al (1993b) amplifient par PCR et séquencent le gène codant pour l'ARNr $5,8 \mathrm{~s}$ et les 2 régions intergéniques (ITS1 et ITS2) chez 2 souches Tox ${ }^{+}$canadiennes, 3 souches Tox ${ }^{+}$australiennes et 2 souches Tox ${ }^{0}$ canadiennes. Les séquences du gène ARNr 5,8 s sont identiques pour toutes les souches, ce qui confirme leur proximité taxonomique. À l'opposé, les séquences des 2 ITS sont nettement différentes chez les Tox $^{0}$ et les Tox $^{+}(71 \%$ de taux de similitude pour I'ITS1 et $82 \%$ pour I'ITS2). Par ailleurs, un très fort taux de similitude des souches $\mathrm{Tox}^{+}$ entre elles est observé (proche de $100 \%$ ), quelle que soit leur origine géographique (Morales et al, 1993b).

Les analyses RFLP de Koch et al (1991) ont porté sur un plus grand nombre d'échantillons puisque 28 souches de provenances diverses sont étudiées. L'hybridation avec de l'ADN provenant de banques génomiques, constituées à partir d'une souche $\mathrm{Tox}^{0}$ et d'une souche $\mathrm{Tox}^{+}$, montre une fois encore un très faible polymorphisme au sein du groupe des souches Tox ${ }^{+}$. Les souches $\operatorname{Tox}^{0}$, quant à elles, sont très nettement séparées en 3 sous-groupes génétiquement distants : NA1, regroupant 4 souches isolées de colza ou de chou et provenant de Nouvelle-Zélande, des États-Unis ou d'Allemagne; NA2, regroupant 4 souches de provenances très diverses (Australie, Canada et Afrique du Sud) et isolées de chou, de navette ou de colza ; et NA3, ne comprenant qu'une souche, isolée de chou aux États-Unis.

\section{Le cas particulier des souches "Thlaspi"}

Parmi les souches isolées de crucifères adventices et caractérisées par Petrie (1969), seules quelques souches isolées de $T$ arvense ont fait l'objet d'analyses moléculaires plus poussées. Rappelons tout d'abord que les souches "Thlaspi" se rapprochent des souches "Brassica» Tox $^{0}$ en ce qu'elles ne produisent pas de sirodesmines in vitro et qu'elles ne se croisent pas avec les souches Tox ${ }^{+}$. À l'opposé, les analyses RFLP permettent de regrouper une souche "Thlaspi" canadienne avec les souches "pathogènes" isolées en Grande-Bretagne (Johnson et Lewis, 1990). L'analyse par électrophorèse en champ pulsé de 2 souches "Thlaspi» montre des profils intermédiaires entre ceux des souches $\mathrm{Tox}^{+}$et $\mathrm{Tox}^{0}$ (Morales et al, 1993a). Toutefois, leurs profils d'hybridation tendent à les rapprocher selon les sondes, soit des souches Tox $^{+}$, soit des 3 souches Tox ${ }^{0}$ analysées par les auteurs.

Le séquençage du gène codant pour l'ARNr 5,8 s confirme la proximité taxonomique de 2 souches "Thlaspi" isolées au Canada et des souches «Brassica» Tox ${ }^{+}$ou Tox ${ }^{0}$ (Morales et al, 1993b). Le séquençage des ITS suggère toutefois que les souches "Thlaspi" forment un groupe distinct des souches "Brassica" mais que celles-ci seraient plus proches des souches "Brassica" Tox ${ }^{0}$ (90 et $95 \%$ de similitude pour les ITS1 et 2, respectivement) qu'elles ne le seraient des souches Tox ${ }^{+}$ 


\section{Analyses protéiques : vers des analyses de routine}

L'électrophorèse des protéines de paroi de 15 souches allemandes montre une variabilité importante au sein des souches Tox ${ }^{0}$ (Hassan et al, 1991).

En utilisant des souches de référence décrites par Koch et al (1991) nous avons développé 3 types d'outils protéiques pour l'analyse de notre collection de souches : i) Western blot (Gall, 1994 ; Balesdent et al, 1994), ii) profils de protéines solubles révélés au nitrate d'argent après séparation par focalisation isoélectrique (IEF) (Balesdent et al, 1992 ; Gall et al, 1994a), et iii) profils de 8 systèmes isoenzymatiques différents (Gall et al, 1994a).

Les profils de protéines solubles discriminent clairement les souches $\operatorname{Tox}^{+}$des souches $\operatorname{Tox}^{0}$ isolées en France : le taux moyen de bandes communes entre profils est de $88 \%$ pour les Tox $^{0}$, de $92 \%$ pour les Tox $^{+}$mais seulement de $46 \%$ entre les 2 groupes d'isolats (Balesdent et al, 1992) (fig 4). Cette première analyse nous a permis de démontrer l'existence des souches Tox ${ }^{0}$ sur colza en France et de montrer que les 2 groupes de souches pouvaient être isolés de périthèces prélevés sur le même débris de culture. Pareillement, les profils obtenus après Western blot et les profils isozymes discriminent clairement les souches $\mathrm{Tox}^{+}$et Tox ${ }^{0}$ (figs 4,5 ). De plus, les Tox ${ }^{0}$ sont elles-mêmes séparées dans tous les cas en 3 sous-groupes correspondant aux groupes NA1, NA2 et NA3, précédemment décrits par Koch et al (1991) à l'aide d'analyses RFLP (Balesdent et Rouxel, 1993 ; Gall et al, 1994a) (figs 4,5). Les analyses factorielles des correspondances (FCA) développées à partir des données isoenzymatiques montrent : i) la

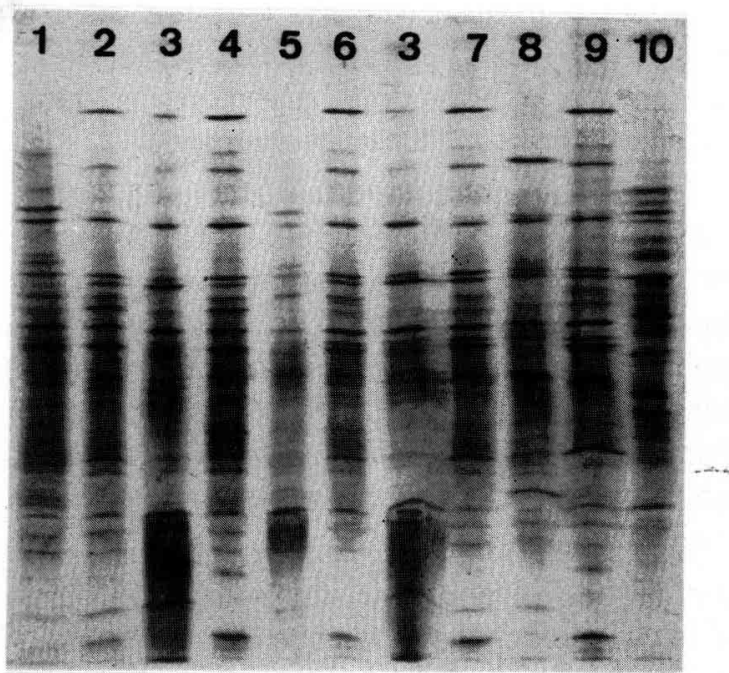

Fig 4. Profils électrophorétiques des protéines mycéliennes solubles de $L$ maculans. Les protéines sont séparées par focalisation isoélectrique sur gel de polyacrylamide de gradient de $\mathrm{pH}$ 4-6,5 et révélées au nitrate d'argent (Gall et al, 1994b). 1 et 5 : souches de référence PHW790 et PHW863, respectivement (Koch et al, 1991, Tox ${ }^{0}$ groupe NA2). 2, 4, 6, 7 et 9 : souches Tox ${ }^{0}$ australiennes. 3 : souche de référence PHW126 (Koch et al, 1991, Tox ${ }^{0}$ groupe NA3). 8 : souche Tox ${ }^{0}$ européenne. 10 : souche Tox $^{+}$

proximité des différentes souches de $L$ maculans, clairement séparées de 3 autres espèces de Leptosphaeria, L conferta, $L$ doliolum var pinguicula et $L$ doliolum var doliolum ; ii) la ressemblance de toutes les Tox ${ }^{0}$ européennes étudiées avec la souche de référence du sousgroupe NA1 (Balesdent et Rouxel, 1993 ; Gall et al, 1994a). Des données plus limitées, portant sur 8 souches Tox ${ }^{0}$ australiennes, issues d'ascospores collectées au champ, suggèrent que celles-ci appartiendraient au sous-groupe NA3 (Balesdent et Rouxel, non publié) (fig 4). Ceci

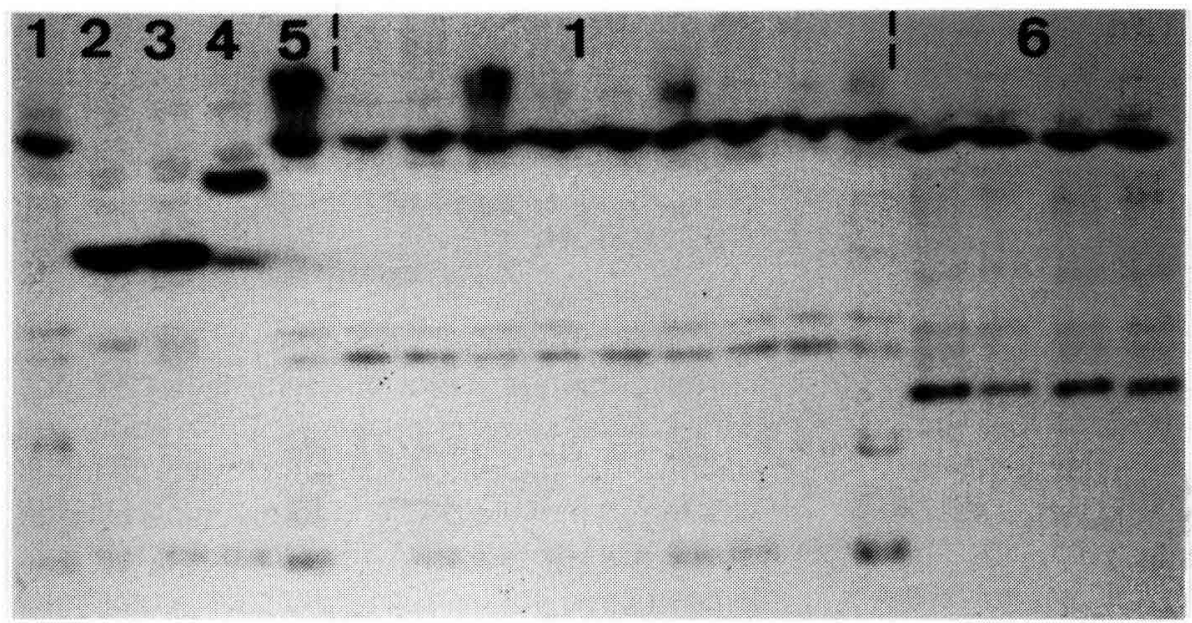

Fig 5. Profils des shikimate déshydrogénases de $L$ maculans. Les isozymes sont séparées par focalisation isoélectrique sur gel de polyacrylamide de gradient de $\mathrm{pH}$ 3-10 (Gall et al, 1994a). 1 : souches Tox ${ }^{0}$ européennes. 2 et 3 souches de référence PHW790 et PHW863, respectivement (Koch et al, 1991, Tox ${ }^{0}$ groupe NA2). 4 : souche de référence PHW126 (Koch et al, 1991, Tox ${ }^{0}$ groupe NA3). 5 : souche de référence PHW129 (Koch et al, 1991, Tox ${ }^{0}$ groupe NA1). 6 : souches Tox ${ }^{+}$. 
pourrait expliquer les divergences de profils RAPD des Tox $^{0}$ australiennes par rapport à ce qui est décrit pour des Tox ${ }^{0}$ d'origine géographique différente (Plummer et al, 1994).

Plus récemment, l'analyse des profils de protéines solubles ou de certains systèmes isoenzymatiques chez 122 souches françaises nous a permis de confirmer que souches $\mathrm{Tox}^{+}$et $\mathrm{Tox}^{0}$ pouvaient être isolées de macules foliaires à l'automne, mais aussi que les 36 souches Tox ${ }^{0}$ caractérisées appartenaient toutes au sous-groupe NA1 (Balesdent, Robin et Rouxel, non publié).

Une telle approche démontre la fiabilité de ces techniques et permet d'envisager une étude à plus grande échelle à des fins de cartographie ou de suivi épidémiologique.

\section{POLYMORPHISME OU COMPLEXE D'ESPÈCES ?}

La situation telle qu'elle se présente à la lumière des connaissances actuelles peut être résumée ainsi :

- Les souches "Brassica» Tox ${ }^{+}$causent en conditions contrôlées, sur $B$ napus, $B$ rapa et $B$ oleracea, les symptômes typiques de la «nécrose du collet des crucifères", à savoir des macules sur organes aériens et une nécrose du collet à un stade plus avancé de la maladie. Ces souches sont au moins présentes en Amérique, Australie et Europe. Elles sont très peu polymorphes selon tous les critères étudiés. Elles présentent enfin des spécificités d'interaction et des relations de type gène-pour-gène avec divers cultivars de Brassica.

- Les souches «Brassica» Tox ${ }^{0}$ sont retrouvées en association avec les Tox ${ }^{+}$sur tous les continents où sévit la maladie. Cette association est très étroite puisque dans certains cas $\mathrm{Tox}^{+}$et Tox ${ }^{0}$ ont été isolées de périthèces différenciés sur un même débris de culture (Balesdent et al, 1992). Elles peuvent être isolées de macules, de débris de culture, voire de plantes apparemment saines. Tout comme les Tox ${ }^{+}$, elles peuvent développer une infection systémique des plantes en conditions contrôlées, mais leur gamme d'hôte est plus étendue. Elles sont morphologiquement indistingables des $\mathrm{Tox}^{+}$mais sur la base d'analyses biochimiques ou moléculaires, elles sont clairement identifiables. Le polymorphisme au sein des Tox ${ }^{0}$ est beaucoup plus important que ce qui est décrit chez les Tox ${ }^{+}$. En particulier, 3 sousgroupes génétiquement distants, NA1, NA2 et NA3 ont été décrits. C'est surtout au Canada, où il semblerait que les souches $\mathrm{Tox}^{+}$soient récemment apparues, que les souches $T_{0 x}{ }^{0}$ ont été étudiées. Toutefois, ces études ont sans doute exclusivement porté sur des souches $\operatorname{Tox}^{0}$ du sousgroupe NA2. À ce jour seules des Tox ${ }^{0}$ NA1 ont été isolées en Europe (Gall et al, 1994a). Cela suggère, si la distance entre NA1 et NA2 est aussi grande que cela a été décrit, que la situation européenne ne peut pas être a priori comparée à la situation canadienne. Par conséquent les études du pouvoir pathogène des souches NA1 et de leur incidence sur le rendement (intervention dans la phase nécrotique de la maladie ou dans le syndrome "pieds secs") doivent être développées en ne s'appuyant qu'avec réserve sur les données des équipes canadiennes. De même, si les données préliminaires concernant les souches $\operatorname{Tox}^{0}$ débouchent sur la constatation que les souches NA3 sont prépondérantes en Australie, nous nous trouverions en présence d'une troisième situation, distincte des 2 précédentes.

- L'analyse détaillée des souches pathogènes de crucifères adventices n'a été effectuée qu'au Canada et, à une exception, ces souches sont morphologiquement indistinguables les unes des autres ou des souches Tox ${ }^{+}$(Petrie, 1969). Seul un nombre très limité de souches "Thlaspi» a été analysé à l'aide des méthodes moléculaires. Même s'il est admis que ces souches sont distinctes des Tox $^{+}$et des autres Tox $^{0}$, les données les concernant restent très confuses, tant en ce qui concerne leur pouvoir pathogène sur Brassica (cf Petrie, 1969 ; Johnson et Lewis, 1990) que leur plus grande proximité avec les Tox $^{0}$ ou les Tox ${ }^{+}$(Johnson et Lewis, 1990 ; Morales et al, 1993b). L'occurrence de telles souches dans d'autres pays que le Canada, la possibilité que les crucifères adventices puissent servir de plantes "réservoir», l'identité éventuelle de certaines de ces souches avec les sousgroupes NA1, NA2 ou NA3, la proximité taxonomique et donc la possibilité d'échanges de matériel génétique avec des souches Tox ${ }^{+}$ou Tox ${ }^{0}$, enfin leur pouvoir pathogène sur colza ou autres Brassica cultivées restent à évaluer.

\section{CONCLUSION}

Nous nous trouvons donc, pour ce pathosystème, en présence d'une quantité d'informations complexes et souvent confuses. Cette confusion remonte aux toutes premières caractérisations de la forme parfaite ou de la forme imparfaite de $\mathrm{ce}(\mathrm{s})$ parasite(s), à la reconnaissance des plantes-hôtes, et aux descriptions de symptômes 
sur diverses espèces de Brassica dans des conditions de culture extrêmement variées. Cette complexité a été amplifiée par un manque de communication entre chercheurs qui a conduit à assimiler des données bibliographiques correspondant à des conditions spécifiques de culture ou d'expérimentation, ou à des souches de l'agent pathogène très différentes.

Au XIXe siècle, différentes espèces de Leptosphaeria ou de Phoma ont été décrites sur Brassica cultivées, puis ont été assimilées à une espèce unique dans un souci de simplification. En définitive, cela ne correspondait-il pas, au moins partiellement, à une réalité ? En effet toutes les données biochimiques ou moléculaires concordent actuellement pour démontrer l'existence de 2 groupes de souches génétiquement distants, et de ce fait un nombre croissant d'auteurs considère qu'il s'agit de 2 espèces distinctes (Koch et al, 1991 ; Taylor et al, 1991 ; Morales et al, 1993b). Cette hypothèse est d'ailleurs parfaitement en accord avec les échecs répétés concernant les tentatives de croisement entre souches $\mathrm{Tox}^{+}$et Tox ${ }^{0}$. Dans la logique d'une telle hypothèse, et compte tenu du polymorphisme révélé chez les Tox ${ }^{0}$, ce n'est pas 2 espèces distinctes qu'il faudrait considérer, mais au moins 4 (Tox ${ }^{+}$, Tox ${ }^{0} \mathrm{NA} 1$, Tox ${ }^{0} \mathrm{NA} 2$, et Tox ${ }^{0}$ NA3), voire 5 s'il s'avérait que les souches "Thlaspi» constituent un quatrième groupe de souches Tox ${ }^{0}$. L'analyse d'une collection mondiale de souches, représentative de cette diversité, à l'aide des techniques les plus informatives, permettra bientôt de répondre à cette question (Séguin-Swartz, 1994).

Malgré l'adhésion de la plupart des équipes à l'idée que l'on est en présence d'au moins 2 espèces, certains auteurs continuent à considérer les souches Tox $^{+}$et Tox $^{0}$ comme 2 pathotypes, ce qui sous-entend a priori que l'on s'adresse à la même espèce fongique (par exemple: Goodwin et Annis, 1991 ; Hassan et al, 1991 ; Xue et al, 1992 ; Morales et al, 1993a). De même, l'utilisation de la terminologie "souches pathogènes" pour $\mathrm{Tox}^{+}$, et "souches faiblement pathogènes» pour $\operatorname{Tox}^{0}$ ne fait que masquer la complexité des relations hôte-pathogène que I'on observe à l'intérieur de chaque groupe, et rend le discours du pathologiste incompréhensible pour l'auditeur non averti de cette complexité : comment nommer, sans générer d'ambiguïté, une souche Tox+ ("souche pathogène") avirulente sur certains cultivars?

L'analyse phytopathologique du “complexe d'espèces $L$ maculans" ne peut être envisagée dans l'immédiat dans sa globalité. Puisque l'on dispose maintenant d'outils de caractérisation des souches fiables, il est temps de reconsidérer chacune des questions posées (sources de résistan$c e$, sensibilité aux fongicides, séquences d'infection au champ...) pour chacun des groupes de souches séparément. Seulement alors d'éventuelles interactions entre ces différents groupes pourront être recherchées. Ce dernier point est particulièrement important à considérer, compte tenu des derniers travaux publiés par Taylor et Borgmann (1994). L'utilisation en tant que sonde d'un élément répété, présent dans le génome des souches $\mathrm{Tox}^{+}$en un grand nombre de copies et considéré spécifique de ces souches, a montré que, dans un cas au moins, cet élément pouvait être retrouvé dans le génome d'une souche Tox ${ }^{0}$. Cette donnée suggère la possibilité, sans doute rare, d'échanges génétiques entre les 2 «espèces» (Taylor et Borgmann, 1994).

\section{REMERCIEMENTS}

Nous tenons à remercier $\mathrm{P}$ Lhoste pour l'aide qu'elle a apportée à la réalisation des travaux de caractérisation, $P$ Chandelier (Protection des végétaux, Nancy) pour l'échantillonnage conséquent de souches de $L$ maculans qu'il nous a fourni, B Howlett (University of Melbourne, Australie) pour les Tox ${ }^{0}$ australiennes ici décrites, G Séguin-Swartz (Agriculture Canada, Saskatoon) pour le développement de I'International Blackleg Network (IBN), GA Petrie (Agriculture Canada, Saskatoon) qui nous a autorisé à citer ici ses résultats non publiés et D Ansan (INRA, Pathologie végétale, Versailles) pour une lecture critique de ce manuscrit.

\section{RÉFÉRENCES}

Alabouvette C, Brunin B (1970) Recherches sur la maladie du colza due à Leptosphaeria maculans (Desm) Ces et de Not. I. Rôle des restes de culture dans la conservation et la dissémination du parasite. Ann Phytopathol 2, 463-475

Alabouvette C, Brunin B, Louvet J (1974) Recherches sur la maladie du colza due à Leptosphaeria maculans (Desm) Ces et de Not. IV. Pouvoir infectieux des pycniospores et sensibilité variétale. Ann Phytopathol 6, 265-275

Annis SL, Goodwin PH (1991) Pectinase genes and isozymes of Leptosphaeria maculans isolates from Canada. Can J Plant Pathol 13, 271 (résumé)

Annis SL, Goodwin PH (1993) The role of polygalacturonidases in blackleg of canola. Blackleg News 1 , 5-6

Austin RB, Flavell RB, Henson IE, Lowe HJB (1986) Molecular biology and crop improvement. A case 
study of wheat, oilseed rape and faba beans. Cambridge University Press, Cambridge, GrandeBretagne, $114 \mathrm{p}$

Badawy HMA, Hoppe HH (1989) Production of phytotoxic sirodesmins by aggressive strains of Leptosphaeria maculans differing in interactions with oil seed rape genotypes. J Phytopathol 127 , 146-157

Badawy HMA, Hoppe HH, Koch E (1991) Differential reactions between the genus Brassica and aggressive single spore isolates of Leptosphaeria maculans. J Phytopathol 131, 109-119

Badawy HMA, Kakau J, Hoppe HH (1992) Temperature and ageing of host tissue affect the interactions between different oilseed rape cultivars and pathotype groups of Leptosphaeria maculans. $J$ Phytopathol 134, 255-263

Balesdent MH, Gall C, Robin P, Rouxel T (1992) Intraspecific variation in soluble mycelial protein and esterase patterns of Leptosphaeria maculans French isolates. Mycol Res 96, 677-684

Balesdent MH, Rouxel T (1993) The use of isozyme electrophoresis for taxonomic analyses within the Leptosphaeria maculans species complex. Blackleg News 1, 4-5

Balesdent MH, Desthieux I, Gall C, Robin P, Rouxel T (1994) Quantification of Leptosphaeria maculans growth in cotyledons of Brassica napus using ELISA. J Phytopathol (sous presse)

Bonman JM, Gabrielson RL (1981) Localized infections of siliques and seed of cabbage by Phoma lingam. Plant Dis 65, 868-869

Bonnet E (1994) Le colza victime de sa mauvaise image. Cultivar 357, 46-48

Boudart G (1978) Phytotoxine et nécrose des hypocotyles de crucifères infectées par Leptosphaeria maculans (Ces et de Not) et sa forme imparfaite Phoma lingam. Phytopathol Z 92, 76-82

Boudart G (1981) Modalités de l'attaque parasitaire des crucifères par Leptosphaeria maculans (Desm) Ces et de Not (fc Phoma lingam) agent de la nécrose du collet. Déterminisme moléculaire du pouvoir pathogène. Thèse, Univ Lille, France, $164 \mathrm{p}$

Brun H, Jacques MA (1990) Le dessèchement prématuré des pieds de colza. Quelques symptômes et agents pathogènes associés. Def Veg 262, 7-12

Brunin B (1970) La nécrose du collet du colza. Rôle étiologique des ascospores de Leptosphaeria maculans (Desm) Ces et de Not. Étude histologique de l'infection. Thèse, Univ Lille, France, $87 \mathrm{p}$

Brunin B, Lacoste L (1970) Recherches sur la maladie du colza due à Leptosphaeria maculans (Desm) Ces et de Not. II. Pouvoir pathogène des ascospores. Ann Phytopathol 2, 477-488

Cunningham GH (1927) Dry-rot of swedes and turnips: its cause and control. $N-Z$ Dep Agric, Bull n ${ }^{\circ} 133$

Darpoux H, Louvet J, Ponchet J (1957) Essais de trajtement des semences de crucifères contre le Phoma lingam (Tode) Desm et I'Alternaria brassicae (Berk) Sacc. Ann Epiphyt 4, 545-557
Delwiche PA (1980) Genetic aspects of blackleg (Leptosphaeria maculans) resistance in rapeseed (Brassica napus). Ph D Thesis, University of Wisconsin, Madison, WI, USA, $144 p$

Desmazière JB (1849) Dix-septième notice sur les plantes cryptogames récemment découvertes en France ; Coniomycètes. Ann Sci Nat Bot 11, 273285

Devys M, Férézou JP, Topgi JP, Barbier M, Bousquet JF, Kollmann A (1984) Structure and biosynthesis of phomenoic acid, an antifungal compound isolated from Phoma lingam (Tode). J Chem Soc Perkin Trans 1, 2133-2137

Férézou JP, Riche C, Quesneau-Thierry A, PascardBilly C, Barbier M, Bousquet JF, Boudart G (1977) Structures de 2 toxines isolées des cultures du champignon Phoma lingam Tode : la sirodesmine $\mathrm{PL}$ et la désacétylsirodesmine PL. Nou J Chim 1, 327-334

Gabrielson RL (1983) Blackleg disease of crucifers caused by Leptosphaeria maculans (Phoma lingam) and its control. Seed Sci Technol 11, 749-780

Gall C (1994) Recherches sur la nécrose du collet des crucifères due à Leptosphaeria maculans. Polymorphisme des populations, analyse de tétrades et interaction avec le colza. Thèse Univ Paris XI, Orsay, France

Gall C, Balesdent MH, Desthieux I, Robin P, Rouxel T (1994a) Polymorphism of Tox ${ }^{0}$ Leptosphaeria maculans isolates as revealed by soluble protein and isozyme electrophoresis. Mycol Res (sous presse)

Gall C, Balesdent MH, Robin P, Rouxel T (1994b) Tetrad analysis of acid phosphatase, soluble protein patterns and mating type in Leptosphaeria maculans. Phytopathology (sous presse)

Gladders P, Musa TM (1980) Observations on the epidemiology of Leptosphaeria maculans stem canker in winter oilseed rape. Plant Pathol 29, 28-37

Goodwin PH, Annis SL (1991) Rapid identification of genetic variation and pathotype of Leptosphaeria maculans by Random Amplified Polymorphic DNA assay. Appl Environ Microbiol 57, 2482-2486

Gugel RK, Séguin-Swartz G, Petrie GA (1990) Pathogenicity of three isolates of Leptosphaeria maculans on Brassica species and other crucifers. Can J Plant Pathol 12, 75-82

Gugel RK, Petrie GA (1992) History, occurrence, impact, and control of blackleg of rapeseed. Can J Plant Pathol 14, 36-45

Hall R (1992) Epidemiology of blackleg of oilseed rape. Can J Plant Pathol 14, 46-55

Hammond KE, Lewis BG, Musa TM (1985) A systemic pathway in the infection of oilseed rape plants by Leptosphaeria maculans. Plant Pathol 34, 557-565

Hassan AK, Schulz C, Sacristan MD, Wöstemeyer J (1991) Biochemical and molecular tools for the differentiation of aggressive and non-aggressive isolates of the oilseed rape pathogene, Phoma lingam. J Phytopathol 131, 120-136 
Henderson MP (1918) The black-leg disease of cabbage caused by Phoma lingam (Tode) Desmaz. Phytopathology 8, 379-431

Hill CB (1992) Blackleg of crucifers. In : Plant diseases of international importance. Vol II. Diseases of vegetables and oil seed crops (Chaube HS, Kumar J, Mukhopadhyay AN, Singh US, eds), Prentice Hall, Englewood Cliffs, NJ, États-Unis, 253-271

Hill CB, Hua XX, Williams $\mathrm{PH}$ (1984) Correlations of virulence, growth rate, pigment production and allozyme banding patterns which differentiate virulent and avirulent isolates of Leptosphaeria maculans. Cruciferae News/ 9, 79 (résumé)

Holm L (1957) Études taxonomiques sur les Pléosporacées. Symbolae Botan Upsalienses 14, 1188

Humpherson-Jones FM (1983) Pathogenicity studies on isolates of Leptosphaera maculans from brassica seed production crops in south-east England. Ann Appl Biol 103, 37-44

Humpherson-Jones FM (1986) The occurrence of virulent pathotypes of Leptosphaeria maculans in brassica seed crops in England. Plant Pathol 35, 224231

Johnson RD, Lewis BG (1990) DNA polymorphism in Leptosphaeria maculans. Physiol Mol Plant Pathol $37,417-424$

Kistler HC, Miao VPW (1992) New modes of genetic change in filamentous fungi. Annu Rev Phytopathol 30, 131-152

Koch E, Badawy HMA, Hoppe HH (1989) Differences between aggressive and non-aggressive single spore lines of Leptosphaeria maculans in cultural characteristics and phytotoxin production. $J$ Phytopathol 124, 52-62

Koch E, Song K, Osborn TC, Williams PH (1991) Relationship between pathogenicity and phylogeny based on restriction fragment length polymorphism in Leptosphaeria maculans. Mol Plant-Microbe Interact 4, 341-349

Krüger W (1983) Oilseed rape. Pests and diseases. Semundo, Hambourg

Lacoste L (1965) Biologie naturelle et culturale du genre Leptosphaeria Cesati et de Notaris. Déterminisme de la reproduction sexuelle. Thèse d'État, Univ Toulouse, France, 234 p

Lacoste L, Louvet J, Anselme C, Alabouvette C, Brunin B, Pierre JG (1969) Rôle de Phoma lingam (Tode) Desm et de sa forme parfaite, Leptosphaeria maculans (Desm) Ces et de Not dans les épidémies de nécrose du collet de colza (Brassica napus $L$ var oleifera Metzer). C R Acad Agric Fr 55, 981-989

Lucas MT, Webster J (1967) Conidial states of British species of Leptosphaeria. Trans Brit Mycol Soc 50, 85-121

McGee DC, Emmett RW (1977) Blackleg (Leptosphaeria maculans (Desm) Ces et de Not) of rapeseed in Victoria: crop losses and factors which affect disease severity. Aust J Agric Res 28, 47-51
McGee DC, Petrie GA (1978) Variability of Leptosphaeria maculans in relation to blackleg of oilseed rape. Phytopathology 68, 625-630

Mengistu A, Rimmer SR, Koch E, Williams PH (1991) Pathogenicity grouping of isolates of Leptosphaeria maculans on Brassica napus cultivars and their disease reaction profiles on rapid-cycling brassicas. Plant Dis 75, 1279-1282

Mengistu A, Rimmer RS, Williams PH (1993) Protocols for in vitro sporulation, ascospore release, sexual mating, and fertility in crosses of Leptosphaeria maculans. Plant Dis 77, 538-540

Meyer W, Lieckfeldt E, Wöstemeyer J, Börner TH (1992) DNA fingerprinting for differentiating aggressivity groups of the rape seed pathogen Leptosphaeria maculans. Mycol Res 96, 651-657

Morales VM, Pelcher LE, Taylor JL (1993a) Comparison of the 5.8s rDNA and internal transcribed spacer sequences of isolates of Leptosphaeria maculans from different pathogenicity groups. Curr Genet 23, 490-495

Morales VM, Séguin-Swartz G, Taylor JL (1993b) Chromosome size polymorphism in Leptosphaeria maculans. Phytopathology 83, 503-509

Müller E (1953) Kulturversuche mit Ascomyceten. I. Sydowia 7, 325-334

Müller E, Tomasevic M (1957) Kulturversuche mit einigen Arten der Gattung Leptosphaeria Ces et de Not. Phytopathol Z29, 287-294

Nathaniels NQR, Taylor GS (1983) Latent infection of winter oilseed rape by Leptosphaeria maculans. Plant Pathol 32, 23-31

Pedras MSC, Abrams SR, Séguin-Swartz G (1988) Isolation of the first naturally occurring epimonothiodioxopiperazine, a fungal toxin produced by Phoma lingam. Tetrahedron Lett 29, 3471-3474

Pedras MSC, Séguin-Swartz G, Abrams SR (1990) Minor phytotoxins from the blackleg fungus Phoma lingam. Phytochemistry 29, 777-782

Petrie GA (1969) Variability in Leptosphaeria maculans (Desm) Ces et de Not, the cause of blackleg of rape. Thèse, Univ Saskatchewan, Canada, $215 p$

Petrie GA (1978) Occurrence of a highly virulent strain of blackleg (Leptosphaeria maculans) on rape in Saskatchewan (1975-1977). Can Plant Dis Surv 58, 21-25

Petrie GA (1988) The rapid differentiation of virulent and weakly virulent strains of Leptosphaeria maculans (blackleg or stem canker) and related pycnidial fungi from Brassica seeds and stems. Can J Plant Pathol 10, 188-190

Petrie GA, Lewis PA (1985) Sexual compatibility of isolates of the rapeseed blackleg fungus Leptosphaeria maculans from Canada, Australia and England. Can J Plant Pathol 7, 253-255

Plummer KM, Howlett BJ (1993) Major chromosomal length polymorphisms are evident after meiosis in the phytopathogenic fungus Leptosphaeria maculans. Curr Genet 24, 107-113 
Plummer KM, Dunse K, Howlett BJ (1994) Nonaggressive strains of the blackleg fungus, Leptosphaeria maculans, are present in Australia and can be distinguished from aggressive strains by molecular analysis. Aust $J$ Bot 42, 1-8

Poiret B, Kollmann A, Bousquet JF (1985) Activités antifongiques de la sirodesmine $\mathrm{PL}$ et deux analogues naturels isolés de Phoma lingam (Tode) Desm. Action antagoniste du zinc. agronomie 5, 533-538

Pound GS (1947) Variability in Phoma lingam. J Agric Res 75, 113-133

Prillieux E, Delacroix G (1890) Note sur le Phoma brassicae. Soc Mycol Fr 6, 114

Régnault Y, Laville J, Penaud A (1897) Cahiers techniques. Les maladies du colza d'hiver. CETIOM, Paris

Rostrup E (1894) Phoma Angriff der Wurzelwächsen. Z Pflanzenkr 4, 322-323

Rouxel T, Chupeau Y, Fritz R, Kollmann A, Bousquet JF (1988) Biological effects of sirodesmin PL, a phytotoxin produced by Leptosphaeria maculans. Plant Sci 57, 45-53

Rouxel T, Kollmann A, Balesdent MH (1994) Phytoalexins from the crucifers. In : Handbook of phytoalexin metabolism and action (Daniel $M$, Purkayastha RP, eds), Marcel Dekker, New York, 229-261

Roy NN (1978) A study on disease variation in the populations of an interspecific cross of Brassica juncea $\mathrm{L} \times \mathrm{B}$ napus $\mathrm{L}$. Euphytica 27, 145-149

Roy NN, Reeves J (1975) Breeding better rape and linseed for Western Australia. J Agric West Aust 16, 93-99

Schäfer C, Wöstemeyer J (1992) Random primer dependent PCR differentiates aggressive from nonaggressive isolates of the oilseed rape pathogen Phoma lingam (Leptosphaeria maculans). J Phytopathol 136, 124-136

Séguin-Swartz G (1994) International Blackleg Network. Blackleg News 2, 7
Sippell DW, Wong RSC, Hall R (1988) Isozyme polymorphisms differentiate isolates of Leptosphaeria maculans virulent and weakly virulent to Brassica napus. Phytopathology 78, 1511 (résumé)

Smith HC (1956) Leptosphaeria napi, the perithecial form of Phoma lingam causing dry-rot disease of Brassicas. N-Z Sci Rev 14, 116-117

Smith HC, Sutton BC (1964) Leptosphaeria maculans, the ascogenous state of Phoma lingam. Trans $\mathrm{Br}$ Mycol Soc 47, 159-165

Sutton BC (1980) The Coelomycetes. Fungi imperfecti with pycnidia acervuli and stromata. Commonwealth Mycological Institute, Kew, Angleterre, 696 p

Taylor JL, Borgmann IE, Séguin-Swartz G (1991) Electrophoretic karyotyping of Leptosphaeria maculans differentiates highly virulent from weakly virulent isolates. Curr Genet 19, 273-277

Taylor JL, Borgmann IE (1994) An unusual repetitive element from highly virulent isolates of Leptosphaeria maculans and evidence of its transfer to a weakly virulent isolate. Mol Plant-Microbe Interact 7, 181-188

Tode HI (1791) Fungi mecklenburgensis selecti. Fasciculus II. p 51, planche XVI, Lüneberg, Allemagne

Tulasne LR, Tulasne C (1863) Selecta fungorum carpologia. Vol 2, La Presse Impériale, Paris, $300 \mathrm{p}$

Venn $L$ (1979) The genetic control of sexual compatibility in Leptosphaeria maculans. Aust Plant Pathol 8 , 5-7

Williams PH, Delwiche PA (1979) Screening for resistance to blackleg of crucifers in the seedling stage. In : Proceedings of a EUCARPIA conference on the breeding of Cruciferous crops. Wageningen, PaysBas, 164-170

Xi K, Morrall RAA, Gugel RK, Verma PR (1991) Latent infection in relation to the epidemiology of blackleg of spring rapeseed. Can J Plant Pathol $13,321-331$ 